\title{
The Food Recall Manual (Ver. 2)
}

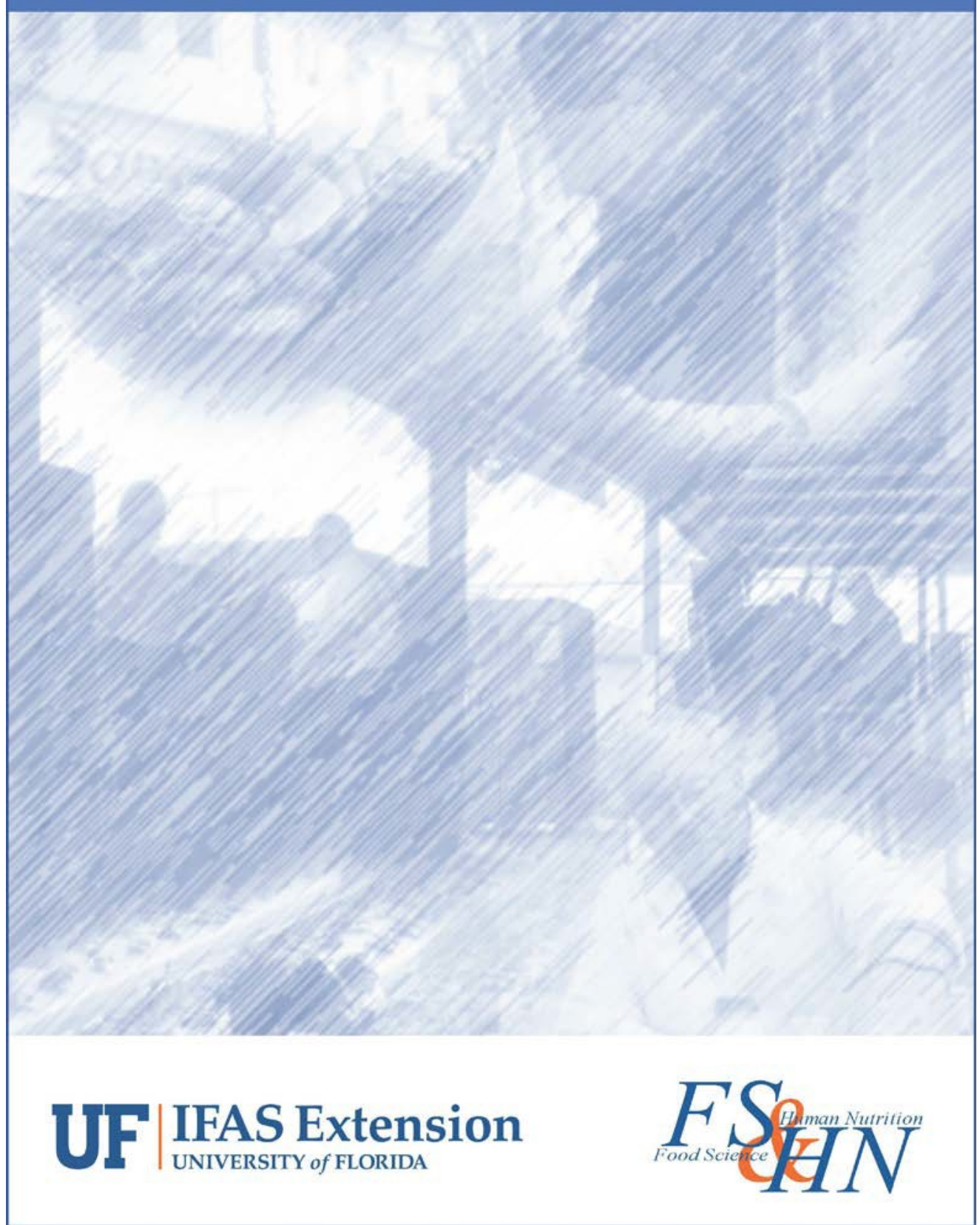

Written and prepared by:

Keith R. Schneider ${ }^{1}$, Renée Goodrich Schneider ${ }^{1}$, Douglas L. Archer ${ }^{1}$, Michelle D. Danyluk $^{1,2}$, George L. Baker ${ }^{1}$, and Chris Thomas ${ }^{3}$

${ }^{1}$ UF/IFAS Department of Food Science and Human Nutrition, Gainesville, FL 2UF/IFAS Citrus Research and Education Center, Lake Alfred, FL ${ }^{3}$ Chris Thomas Communications, Boise, ID/Seattle, WA 
RECALL TEAM

Date Assigned:

Assignments

Person

Contact Information

Senior Operations Manager

Alt. Manager

Publicity \& Public Relations

Alt:

Marketing Specialist

Alt:

Scientific Advisor

Alt:

Logistics and Receiving Specialist

Alt:

Quality Assurance Specialist

Alt:

Accountant

Alt:

Attorney

Alt:

Administrative Support

24- hour Food Delivery

Miscellaneous 


\section{Recall Action Visual Guide}

The guide below is a quick-use reference tool to help user find the pertinent sections in the Recall Binder. A comprehensive Table of Contents appears on the next page.

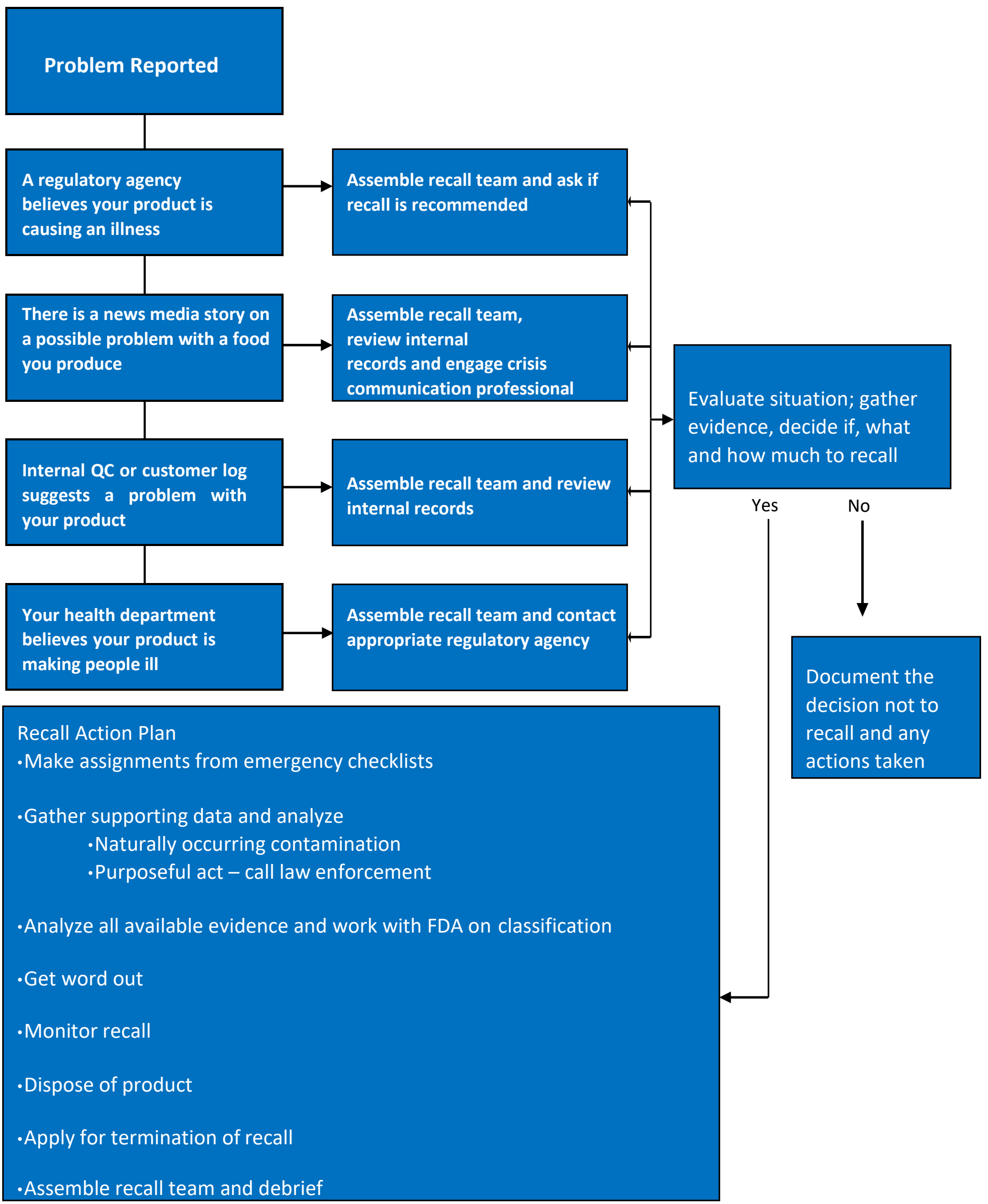




\section{THE FOOD RECALL MANUAL}

\section{TABLE OF CONTENTS}

Introduction - Why a Food Recall Manual? .................................................................... 1

Chapter 1 - Food Safety and Your Legal Responsibility ....................................................... 2

Chapter 2 - Before the Recall: Prevention and Planning ........................................................25

Chapter 3 - The Recall Begins: Investigation and Cooperation..............................................47

Chapter 4 - After the Recall: Legal Liability and Rebuilding Trust............................................62

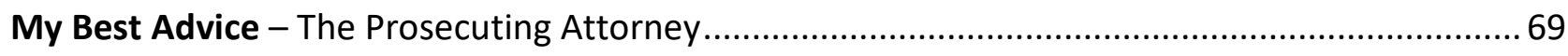

My Best Advice - The Crisis Communications Expert ...................................................... 74

My Best Advice - The Recall Team Member....................................................................................... 81

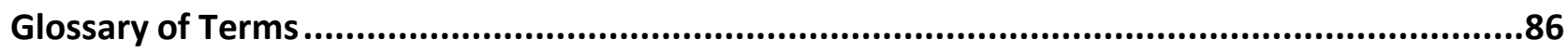

Appendices

1-1 Links to Important Food-Recall and Food-Safety Resources .............................109

1-2 Call Sheet: For Persons Claiming an Illness or Injury ........................................111

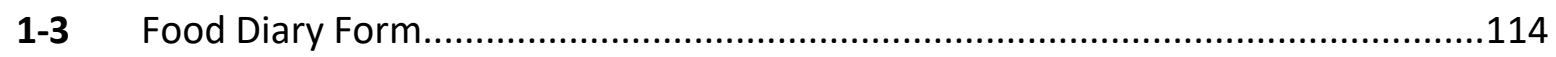

1-4 Call Sheet: In Case of a Telephone Threat.................................................... 117

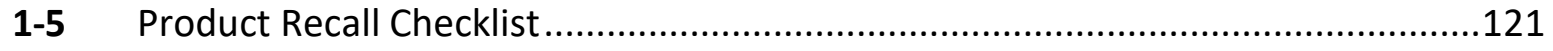

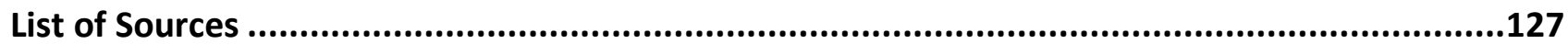




\section{Introduction: Why a Food Recall Manual?}

Any business of any size involved in the manufacture, processing, packing, holding, or delivery of food to humans needs to understand and address food recalls. Recalls are a means to remove potentially hazardous products from the marketplace or from consumers' homes. This manual has been developed to assist businesses with the recall process. The manual is based on the information provided by important food recall and safety resources listed in Appendix 1-1. Bolded terms and acronyms are all explained in a glossary at the end of this manual.

The mandatory food recall authority of the Food and Drug Administration (FDA) went into effect when the Food Safety Modernization Act (FSMA) was enacted on January 4, 2011. Section 423 of the Federal Food, Drug and Cosmetic Act (FD\&C Act), as added by Section 206 of FSMA, gives FDA the authority to order a responsible party to recall an article of food where FDA determines there is probable risk to the consuming public if a food product is not withdrawn from the market. No one in the food industry likes to think about product recalls, but recalls are necessary to protect both public health and a company or brand reputation. The number and scope of food recalls is increasing as regulatory agencies implement new toolssuch as whole-genome sequencing of microorganisms, a technology that permits linking illnesses to a food with a whole new level of sensitivity and accuracy.

Under the FSMA, preparations for product recall are mandated for all operations that manufacture, process, pack or hold foods; in short, any food operation that must register with the FDA. Under FSMA there are many exempted operations, such as farms. However, under its

broad authorities to protect the public health, recalls can affect even exempted operations such as a farm should FDA conclude that a threat to public health exists. FSMA also gives the FDA a new authority, to order a product recall. 


\section{Chapter One}

\section{Food Safety and Your Legal Responsibility}

If you discover or even suspect a problem with the food product you are manufacturing, distributing or selling, the goal is to keep that product from reaching the consumer-or if it has shipped, to inform consumers who might have purchased, received or used it. Generally, you'll need to get the product out of the supply chain as quickly as possible.

Your ultimate legal and ethical responsibility is to do whatever you can to protect consumers' health and well-being, in addition to investigating the cause of the problem and fixing it. Exactly what do you have to do, and who requires it? Those are the pertinent questions, and the focus of this wide-ranging chapter.

\section{The Regulatory Climate}

In a 2016 audit of 30 food recall actions from recent years, for both domestic and imported products, the US Office of Inspector General (OIG) criticized the FDA for not requiring recalls quickly enough in cases of foodborne illness or deaths. The OIG found the FDA's policies and procedures didn't include a specific timeframe and manner for voluntary recalls, and said the agency should be more aggressive in recall cases. The FDA responded that each recall situation is different and complex, so setting standard timeframes and procedures wouldn't be appropriate, (https://blogs.fda.gov/fdavoice/index.php/2016/06/our-goal-in-enforcing-foodsafety-a-rapid-science-based-response/).

An ever-expanding global economy has brought even greater challenges. The FDA estimates the amount of food imported to the United States has doubled since 2003, and FSMA requirements include the ambitious Foreign Supplier Verification Programs (FSVP), described later in this chapter. The agency has already said it doesn't have enough investigators to perform the number of foreign inspections required under the FSVP. At the same time, more food products are available online-adding layers of complexity to any recall action.

FDA responses can vary between regions, so it is difficult to state hard-and-fast rules about the agency's behavior and expectations. What does seem to impress every level of 
official-and any outside consultants you may contract-are companies that are well-organized and responsive to questions and requests.

Federal agencies are coordinating their efforts in cases of food-related epidemics, natural disasters, and terrorist events. This is no small feat among more than 20 agencies. Because many foodborne illnesses are preventable-and/or related to food products or settings not covered by FSMA-that underscores the industry's need to do more as well.

\section{Government Agencies for Food Safety Issues}

Regulatory agencies serve as extra sets of eyes and ears in the food-distribution chain. The inspections and complaint collection they perform help businesses in the food industry protect brands and preserve consumer loyalty. These agencies can link cases that may otherwise appear to be isolated and objectively gather data that can help pinpoint potential problems before they endanger consumers and companies.

These agencies take non-compliant businesses to task-and to court-to protect the food industry and public health. Your interactions with them will ultimately determine whether your business survives a product recall.

\section{State and Local Agencies}

In addition to cooperating with the FDA, businesses in the food industry must also know and follow state and local food-safety laws. Approximately 80 percent of all food-establishment inspections are conducted by a local or state government agency, often by contracted agreements with the FDA.

Most food-related businesses get permits or licenses from a state (or local) regulatory agency and are subject to routine safety and sanitation inspections by this agency. Depending on a business's location, this could be the state agriculture department or health department, another state agency, or a local (city or county) health department. When inspections by these agencies turn up something questionable, violations may result in fines or other actions.

Other regulators may ask for information or to inspect the facility because an end user

of a food product (a restaurant, for instance) has reported an illness outbreak, and the agency 
that regulates the end user needs to rule out (or possibly identify) companies at other steps in the supply chain as possible sources of the outbreak.

State or local epidemiologists (usually affiliated with county or state health departments) might play a role in identifying foods responsible for illness outbreaks because often their agencies are where consumers or their health-care providers first report illnesses.

More than two dozen states have their own meat and poultry inspection programs. In some cases, the state inspectors are authorized to work on behalf of the Food Safety and Inspection Service (FSIS), a division of the United States Department of Agriculture (USDA). The FSIS can ask a state for assistance under a law known as the Talmadge-Aiken Act. FSIS reviews each state's inspection program annually to ensure it is at least equal to federal standards. Local agencies sometimes report problems to the federal agencies for further investigation, but a state does not have to ask for federal assistance in investigating a disease outbreak.

In many cases, a federal agency calls on state agencies to assist in enforcement. State agencies most often license or permit food processing and handling facilities - so they have the ability to pull the license, effectively stopping the operation. In addition, many state agencies can do what is known as a "stop-sell" or "stop-sale," which prevents the marketing of potentially violative products.

\section{What Do Inspections Cover?}

FDA investigators or inspectors undergo rigorous training and accumulate field experience that often guides their actions. It is nearly impossible to determine exactly what an investigator will be looking for at your facility, since seldom are any two food facilities identical, but we can point to a typical inspection procedure as laid out in the Investigations Operations Manual (IOM) on the FDA website. (http://www.fda.gov/ICECI/Inspections/IOM/.) Chapter 5 of the IOM, Establishment Inspections, goes into great detail about what is required of the inspector; Subchapter 5.4 covers food and food inspections. These should be required reading for food facility managers and recall team members.

Another way to get acquainted with what investigators look for is to peruse the FDA's Inspections Observation Database (Online at: 
https://www.fda.gov/iceci/inspections/ucm250720.htm). It contains the online FDA Form 483, used by the agency to notify a company about objectionable conditions. It takes a few clicks to find them, but many of these documents list specific observations of the investigator, such as:

- Crusted material accumulated in cracks of conveyor belt, a food contact surface.

- Incoming raw material is transported through the area where finished productis packaged.

- Condensate observed dripping on product conveyor line from overhead pipes.

Facility managers, particularly quality and safety assurance coordinators, should practice proactive food safety self-education by accessing, regularly reviewing and learning from this database. Depending on the situation, the law or ordinance, and the inspector, an inspection can be a very thorough and time-consuming process-and for the company and its workers, frustrating and unnerving. So, it's smart to think of inspections as another layer of quality control and to be open to the inspectors' findings and suggestions.

Under FSMA, the FDA investigators' authority has broadened substantially. An inspection might now entail looking at the company's Food Safety Plan, with all its attendant documentation. Inspections can trigger recalls-and recalls can trigger inspections-so it's best for your managers to be well acquainted with FDA procedures, responsibility and authority.

\section{Federal Agencies}

On the federal level, the Centers for Disease Control and Prevention (CDC) maintain three national networks that receive and coordinate health-related data from all the states. This is another critical step in tracing the distribution of potentially hazardous products.

- The Foodborne Diseases Active Surveillance Network (FoodNet) consists of programs in 10 states doing regular surveillance and tracking of the epidemiology of foodborne illnesses. "Active" means researchers contact health officials and look prospectively for problems or outbreaks instead of relying only on incoming reports. (Online at: https://www.cdc.gov/foodnet/index.htm)

- The National Antimicrobial Resistance Monitoring System for Enteric Bacteria 
(NARMS) is a network of public health labs that routinely send microbe samples (e.g., Salmonella, Shigella, Escherichia coli (E. coli) O157:H7 and others) to the CDC for susceptibility testing - that is, to see if they are becoming resistant to conventional treatments, such as antibiotics. (Online at https://www.cdc.gov/narms/)

- The National Molecular Subtyping Network for Foodborne Disease Surveillance (PulseNet) is a network of public health laboratories in the United States and Canada that can perform a specific DNA test (called pulsed-field gel electrophoresis, PFGE) on foodborne bacteria. The results of this "fingerprint" can be used toidentify specific strains and origins of bacteria. The labs make the results available on PulseNet for quick comparison. (Online at https://www.cdc.gov/pulsenet/)

- PulseNet International is a network of more than 120 pulsed-field gel electrophoresis laboratories in 82 countries similar to the one described above. (Online at http://www.pulsenetinternational.org/

Several groups work within the CDC to keep tabs on food safety issues, collaborate on research, and report their findings. Together, they make up the National Center for Emerging and Zoonotic Infectious Diseases (NCEZID), which includes; a Division of Foodborne, Waterborne and Environmental Diseases (DFWED) (Online at (http://www.cdc.gov/ncezid/dfwed/index.html), and an Outbreak Response Team (ORT) (Online at http://www.cdc.gov/ncezid/dfwed/orpb/ort.html), as well as other branches. Other, external government organizations also collaborate with the CDC. The ones food processors are most likely to come into contact with include the following:

- The FDA is part of the United States Department of Health and Human Services (HHS). FDA, specifically its division, the Center for Food Safety and Applied Nutrition (CFSAN), is responsible for the safety and purity of all food products (including chewing gum, shell eggs, pet food, and animal feed), with the exception of meat, poultry, and egg products. This means about 80 percent of the US food supply-produced domestically and imported-falls under FDA purview. 
Additionally, the FDA has now set up the whole genome sequencing program that is fast becoming a major tool in surveillance (http://www.fda.gov/Food/FoodScienceResearch/WholeGenomeSequencingProgra mWGS/ucm403550.htm).

- FSIS is part of the USDA. FSIS is responsible for the wholesomeness and safety of meat, poultry, and egg products and inspects thousands of processing plants annually.

- The Animal and Plant Health Inspection Service (APHIS) is also part of the USDA. APHIS is charged with protecting against plant and animal pests and diseases.

- The Environmental Protection Agency (EPA) regulates pesticide use and is responsible for establishing safe standards for pesticide residues in raw agricultural commodities and in foods sold in interstate commerce. (The FDA and USDA agencies monitor food products for pesticide residues and enforce EPA regulations.)

When the CDC or any of these agencies suspect a disease outbreak, their responsibility is twofold: to identify the source of the problem, and, in cooperation with regulatory agencies, to stop it from spreading as quickly as possible.

Inspection of food-processing facilities is usually left to the FDA or FSIS, but in cases of a disease outbreak, the CDC also has the authority to send an outbreak investigation team to conduct investigations involving food businesses, as well as homes of people who claim to be victims. The team collects medical information, analyzes bacteria isolated from patients, and, if necessary, notifies state and local officials.

The CDC might investigate multi-state disease outbreaks, if asked by individual states. CDC employees are not legally allowed to testify in court about the data they collect, but the actual data may be used in court, either to prosecute or defend a company accused of manufacturing, distributing or selling unhealthful products.

The USDA FSIS, coordinating with the FDA, launched a Food Emergency Response Network (FERN) in 2005. Numerous federal agencies are FERN partners. Its mission, according to its website (https://www.fernlab.org/) is to "establish and maintain America's laboratory 
infrastructure in order to better detect and respond to bioterrorism agents at the local, state, and federal levels..." This brings us to the next level of agency involvement in food safety.

\section{If Bioterrorism Is Suspected}

Food security crises-terrorism, extortion, product tampering-bring other agencies into a food safety case. These include:

- The Federal Bureau of Investigation (FBI) is routinely alerted in all product-related investigations that involve extortion, significant false reports, death or seriousinjury and/or terrorism threats.

- United States Customs and Border Protection (CBP) isn't only about securing US borders and deporting people who are in the United States illegally. It has a forensic division, Laboratories and Scientific Services, providing crime-scene documentation and lab testing for law enforcement and trade compliance.

- The Department of Homeland Security (DHS) lists the food industry as part of 17 "critical infrastructure sectors," and its responsibilities for protecting the nation's food sources are outlined in Homeland Security Presidential Directives (HSPD) 7 and 9.

DHS has said its policy is to "prioritize its efforts in accordance with risk." Quoting from a 2007 manual, DHS' Role in Food Defense and Critical Infrastructure Protection, risk includes three elements, listed here because they're also good basic guidelines for assessing any company's risks:

- Threat. The intention and capability of an adversary to undertake actionsthat would be detrimental to critical infrastructures.

- Vulnerability. A weakness in the design, implementation, or operation of an asset or system that can be exploited by an adversary, or disrupted by a natural hazard or technological failure.

- Consequence. The result of a terrorist attack or other hazard that reflects thelevel, 
duration, and nature of the loss resulting from the incident.

Additionally, the nation's laboratories that might be called on for testing in emergency situations are organized into an Integrated Consortium of Laboratory Networks (ICLN) (https://www.icln.org/), coordinated through DHS. These include four subcategories for their various specialties:

- The Laboratory Response Network (LRN)

- The National Animal Health Laboratory Network (NALHN)

- The National Plant Diagnostic Network (NPDN)

- The Environmental Laboratory Response Network (ELRN)

\section{Bioterrorism-Related Mandates and Legislation}

The Homeland Security Presidential Directive 9 (HSPD-9) became law in January 2004. Its name, Defense of U.S. Agriculture and Food, sums up its mission. The same year, a Food and Agriculture Sector Coordinating Council (FASCC) was formed. A government coordinating council and private-sector coordinating council meet quarterly to work together on fooddefense strategies, best practices and how to communicate them.

Congress had already passed PL 107-188, The Public Health Security and Bioterrorism Preparedness and Response Act (aka Bioterrorism Act), in 2002. The legislation was particularly directed at food imports, to enhance the FDA's overall effectiveness to protect against food adulteration. But at the time, the domestic food-processing industry raised concerns that the new rules were burdensome, and changes were recommended and adopted.

The final rules took effect in 2003 and 2004 and were further strengthened by the passage of FSMA in 2011. The law now performs three actions:

- Gives the FDA administrative detention authority to prevent a food product or ingredient from entering the market if there is credible evidence or information of threat of adulteration or misbranding. The product can be held for "a reasonable period, not to exceed 20 calendar days," and an additional 10 calendar days ifmore time is required to institute a seizure or injunction. 
- Requires facilities that manufacture, process, pack, and/or hold food to register with the FDA-although the information required in the registration is minimal, and major business categories are exempt. (These include some farms, restaurants, retail food establishments, nonprofit food preparation and service, and fishing vessels that do not process their catch.)

- Outlines the types of records that companies must keep and make available to the FDA if requested.

We'll elaborate on FSMA later in the manual.

\section{The Federal Anti-Tampering Act (FATA)}

The Federal Anti-Tampering Act (FATA) outlines criminal penalties not only for product tampering as "malicious mischief," but for "knowingly communicating false information that a consumer product has been tainted." It is enforced by the FDA and/or USDA.

FATA makes it a federal crime to tamper with consumer products and authorizes the FDA to investigate product tampering allegations. The law contains five violations:

- Tampering, or attempted tampering, with a consumer product withreckless disregard for the risk of death or bodily injury

- Tainting a consumer product with intent to cause serious injury to the business or to any person

- Knowingly communicating false information that a consumer product has been tainted

- Knowingly threatening to tamper with a consumerproduct

- Engaging in conspiracy to tamper with a consumer product

Tampering, or even the threat of tampering, is very serious business. It must be reported to the Division of Emergency and Investigational Operations (DEIO) of the FDA. FDA Regional offices will take their probe a step further, notifying their region's Office of Criminal Investigations $(\mathrm{OCl})$ field staff. The $\mathrm{OCl}$ then deals with other law enforcement agencies and keeps them updated as necessary. 


\section{Food Safety Laws and Rules}

State and local food safety ordinances vary widely, so there's no way to cover them all here. However, most of these agencies use the federal food safety laws as their basic guidelines. In addition to city and county ordinances and state laws, there are federal laws that govern food-related product quality and/or contamination. The pertinent federal acts or legislative activities for food safety are summarized here.

\section{The Food Safety Modernization Act (FSMA) of 2011}

FSMA is a series of rules developed to address the potentially lethal combination we've already touched on in this manual-a growing number of foodborne illness outbreaks in the United States, the possibility of increased terrorism risks involving the nation's food supply, and the plethora of imported food products and ingredients.

Congress had already passed a Public Health Security and Bioterrorism Preparedness Response Act in 2002 that allowed the FDA to detain food items that might pose health threats to humans or animals. But FSMA takes the FDA's authority a big step further, giving the agency mandatory recall authority for all food products, plus the increased ability to use administrative detention and/or suspend a facility's registration to keep potentially unsafe products off the market.

In addition to stronger enforcement powers, the FDA now has increased responsibility for preventing problems. FSMA gives FDA the mission of mandating comprehensive controls for food processors and manufacturers to prevent health and safety problems, both for human and animal foods-including requiring them to address vulnerabilities to tampering or terrorist acts.

The Current Good Manufacturing Practice, Hazard Analysis, and Risk-Based Preventive Controls for Human Food and a similarly named document covering "Food for Animals" - often referred to as FSMA's Preventive Controls Rules-most definitely affect your company's recall planning. Simply, if you've identified a hazard in your system that requires a preventive control, then you must have a recall plan.

FSMA also requires the FDA to inspect facilities regularly for compliance, and to do so more frequently than it was required to do in the past for some types of food products produced. FSMA expanded the FDA's regulatory authority to include farms that grow fruits and 
vegetables. The extent of federal regulation depends in some cases on the size and output of the farm, but FSMA includes establishing what the FDA calls "science-based standards for growing, harvesting, packing, and holding produce on domestic and foreign farms."

As if that isn't a big enough job, the new FSVP requires food importers to verify that they're using "the same level of public health protection as that required of U.S. food producers."

And finally, FSMA makes sanitary transportation a priority to keep food safe in transit. All of this leads to FSMA also establishing a certification program for third-party inspectors who assist the FDA with an enormous increase in the need for food safety inspections and audits.

\section{The Federal Food, Drug, and Cosmetic Act (FD\&C Act)}

The FD\&C Act was enacted in 1938. Its primary intent is preventing adulteration or misbranding of food products in interstate commerce, and it's enforced by FDA. The FD\&C Act sets the framework for FDA regulations, codified and published under the Code of Federal Regulations (CFR), Title 21. For example, current Good Manufacturing Practices (CGMPs) published under 21 CFR 117 (formerly 21 CFR 110) provide the sanitation inspection requirements used by the inspecting agency. Amendments to the FD\&C Act have resulted from FSMA activity. The FD\&C Act was amended to include a new Section 418, to require what the FDA describes as modernizing the CGMPs - creating "science-based minimum standards for conducting a hazard analysis, documenting hazards, implementing preventive controls, and documenting the implementation of the preventive controls" - for food safety as part of FSMA.

As a result of FSMA, the FD\&C Act was also amended to require that food manufacturing, processing, packing or holding facilities in the United States register every other year with the FDA. As we have mentioned, the FDA can suspend the registration if the agency determines that a food has "a reasonable probability of causing serious adverse health consequences or death to humans or animals" or if the facility:

- Created, caused, or was otherwise responsible for such reasonable probability; or

- Knew of, or had reason to know of, such reasonable probability; and packed, received, or held such food. 
Under the FD\&C Act, the FDA has several enforcement options, including judicial (involving the US Marshalls Office and the court system) and non-judicial actions:

- Judicial actions may include criminal action (clearly defined in FD\&C Act) or civil action such as an injunction or a seizure. An injunction is a court order requiring a person to refrain from certain specified actions; an injunction can be used to stop a food manufacturer from continuing to manufacture products. A seizure, by definition, is an in rem action (i.e., an action against the goods involved and not against any business or business entity) and is used to remove violative products from the marketplace.

- Non-judicial actions include product recalls, warning letters, and/or various types of publicity, including mentions in the weekly FDA Enforcement Reports.

\section{The Reportable Food Registry (RFR)}

Section 417 of the FD\&C Act took effect in 2009, as the FDA puts it, "to provide a reliable mechanism to track patterns of adulteration in food in order to support efforts by FDA to target limited inspection resources to protect the public health." In short, the FDA acknowledges it can't be everywhere and needs some help prioritizing where there might be problems.

The RFR requires a responsible individual or party (whoever submits Food Facility Registration information for a company) to report any instance of "reasonable probability that the use of, or exposure to, an article of food will cause serious adverse health consequences or death to humans or animals." The FDA says the report must be made "as soon as practicable, but in no case less than 24 hours after" the potential problem has been determined. The RFR does not accept reports from consumers, only from registered food facilities or public health officials. Foods must be reported only in regard to possible health-related problems-the types of things that might lead to a recall, such as undeclared allergens or microbial contamination.

Each report is assigned a number, known as an Individual Case Safety Report (ICSR), which is then used to submit any updates related to the case. 
Reporting is done online at https://www.safetyreporting.hhs.gov. For more information, you can visit the RFR Center for more details, at http://www.fda.gov/Food/ComplianceEnforcement/RFR/default.htm. The FDA notes that any RFR submission will not be viewable by other submitters.

Companies are exempt from filing an RFR report only when all three of the following criteria are met:

- The problem originated within the company.

- The company detected the problem before the product was transferred to anyother person.

- The company corrected the problem or destroyed the product.

In its fifth year (2014), the RFR received 909 reportable food entries; most involved baked goods, and almost half were related to undeclared allergens.

\section{The Meat, Poultry, and Egg Inspection Acts}

The federal acts enforced by the FSIS include the Federal Meat Inspection Act (FMIA), enacted in 1906, the Poultry Products Inspection Act (PIA), enacted in 1957, and the Egg Products Inspection Act (EPIA), enacted in 1970. The FMIA and PIA (also termed the Wholesome Meat Act of 1967 and Wholesome Poultry Act of 1968) were amended to provide for federal (or equivalent) inspection of meat and poultry facilities that are not involved in interstate commerce. FSIS regulations for enforcing these acts are published and codified in the CFR, Titles 7 and 9.

FSIS inspection authority has been greatly expanded to meet the growing responsibilities posed by bioterrorism threats and increases in food imports. This includes strengthening FSIS' ability to share information and technology with other agencies, and improving its ability to inspect international meat, poultry, and egg products "at points of origin and at ports of entry."

In general, the FMIA and PIA govern safety, sanitation, wholesomeness, packaging and labeling of meat, and poultry products, including rules about the humane slaughter of animals 
and safe transporting of food throughout the steps of processing. The EPIA governs pasteurization and sanitation requirements in egg-product processing facilities. The acts enforced by FSIS were among the first to address safety and cleanliness of food processing plants, including equipment, evidence of pests and rodents in every step of production, employee hygiene, and cross-contamination in product handling. They also cover mislabeling of products and require FSIS to enforce product uniformity standards. As an example, a can of chili con carne (chili with meat) must meet certain standards for specific quantities of meat and fat to ensure product consistency, no matter where it is manufactured.

Plants under FSIS inspection must apply for the inspection program and must demonstrate their ability to meet the agency's sanitation, facility, and operational standards. The plants must also show they have preventive systems in place to ensure the production of safe, unadulterated food. In exchange, the products from these plants are labeled with a Mark of Inspection - a seal of approval, of sorts - indicating they have passed federal inspection or the equivalent. Inspections are done by FSIS personnel, who are most often resident inspectors with full-time offices within the inspected facility.

If FSIS inspectors find a problem, they write a Noncompliance Report (NR) of a Process Deficiency Record (PDR) explaining the problem and notifying the plant manager that action must be taken to correct it. For the most part, a plant can continue to operate while the problem is being remedied. However, when there are repeated or serious problems, FSIS Compliance Officers can take more stringent action, such as:

- Detain products that have already been produced and shipped but may be unsafethat is, forbid them to be sold for human consumption. (After a product detention, FSIS has 20 days to ask a federal court for permission to seize the product.)

- Issue a Letter of Warning (LOW), telling anyone who makes, distributes, stores, or sells the product in question that FSIS "may seek criminal action" based on continued violations.

- Withhold marks of inspection - without that official mark, the product cannot be sold.

- Suspend inspection of the plant temporarily, which also effectively means a 
shutdown of part or all of a plant's operations. The term used in a suspension is that the plant is being "held in abeyance" until the problem is remedied.

- Withdraw inspection entirely, which means any product that comes from the plant is no longer USDA-approved for sale and, therefore, cannot be sold.

- Take judicial or non-judicial actions using procedures similar to thosedescribed above for FDA.

FSIS has a two-part system for inspecting imported meat, poultry, and egg products:

1. FSIS monitors the laws and food-safety controls within the exporting country to be certain they are equivalent to those of the United States and grants them the ability to export to the United States, and,

2. FSIS inspects random lots of incoming product to verify that the exportingcountry's system is working.

Violative food that does not meet the US health and safety guidelines is required to be sent back to its source, destroyed, or, in some cases, converted to animal food.

\section{The Food Allergen Labeling and Consumer Protection Act (FALCPA)}

This 2004 law impacts all aspects of the food industry, including food retailers such as supermarkets that package and label foods for sale at their delis, bakeries, and so on. It requires that these companies-including what are termed "co-manufacturers of store-brand products" - comply with federal food allergen labeling requirements, which is meant to address the food safety risk of undeclared food allergens.

As the Food Marketing Institute has put it, "food allergens are food safety risks that impact everyone in the food industry." As previously noted, almost half of the 2014 RFR incidents were related to undeclared food allergens. Appropriately, the FDA 2013 Food Code (https://www.fda.gov/Food/GuidanceRegulation/RetailFoodProtection/FoodCode/ucm374275. $\underline{\mathrm{htm}}$ ) requires that restaurant and retail food-service managers know the eight major allergens and the seriousness of allergic reactions and understand the ingredients in which allergens 
might be present and how they might appear on a food label. Food allergen mislabeling is a common cause of food recalls.

\section{Hazard Analysis Critical Control Point (HACCP) and Food Regulation}

In the 1990s, federal regulatory agencies embarked on programs to require the Hazard Analysis Critical Control Point (HACCP) system in certain segments of the food industry. A critical control point (CCP) is any point in a food manufacturing or preparation process at which a loss of control may result in a health risk.

Created in the 1950 s and early 1960 s, HACCP is a seven-step risk management system:

1. Identify hazards and assess their severity and risk.

2. Identify CCPs in the process.

3. Determine the critical limits $(\mathbf{C L})$ for each CCP.

4. Put processes in place to monitor the CCPs and record the data.

5. Take corrective action whenever monitoring indicates a $\mathrm{CL}$ has exceeded determined minimum or maximum limits.

6. Establish verification procedures to ensure the system is working.

7. Establish record-keeping procedures and maintain thorough documentation.

The FDA has clearly embraced HACCP with requirements for seafood facilities (21 CFR 123), and for fruit and vegetable juice facilities (21 CFR 120). In general, FDA HACCP rules require facilities to operate under an acceptable HACCP program (absence of a HACCP plan is considered adulteration under the FD\&C Act); appropriately train all personnel, and comply with specific prerequisite programs (e.g., CGMPs, sanitation control procedures). The FDA over the years has been involved in pilot HACCP programs with a variety of food industries.

The FSIS HACCP rule for meat and poultry (9 CFR 417) became effective in 1996. In addition to requiring the HACCP system, this very detailed rule (often termed the "Mega Reg") requires that all meat and poultry plants develop written Sanitation Standard Operating Procedures (SSOPs); mandates E. coli testing for slaughter plants; and sets standards for Salmonella risk reduction for slaughter plants and ground-meat producers. 
Fun with Letters: HACCP and FSMA; PCHF and FSPCA

Acronyms abound in the world of food safety. The HACCP process continues to be the global standard, but you might say it now has a "cousin" based on FSMA's Preventive Controls for Human Food, or PCHF. The PCHF rule requires companies to focus on preventing food contamination and mitigating any risk of product tampering or other security concerns. To complicate matters, the PCHF rule training curriculum is associated with the Food Safety Preventive Controls Alliance (FSPCA). Often you'll hear this training referred to as Preventive Control Qualified Individual (PCQI) training. For more information on FSPCA, visit

\section{https://www.ifsh.iit.edu/fspca.}

HACCP (and related processing-oriented programs) was originally designed to ensure the safety of canned foods, juices, and seafood, while FSMA PCHF requires a wider range of food companies to scrutinize a broader range of activities under FSMA. The updated components (as mentioned, these are also known as CGMPs) in 21 CFR 117 include:

- A written food-safety plan

- A hazard analysis

- Preventive controls

- Process monitoring

- Corrective actions and corrections

- Verification

- A supply-chain program

- A recall plan, and

- Associated records

So, while the HACCP system is a solid first step, many food processing companies will need to ensure they also comply with the FSMA PCHF to meet the new FSMA requirements.

A June 30, 2016, article in Food Quality and Safety Magazine (by Laura Nelson) puts it well: "HACCP documents need to be dusted off and reassessed to include radiological hazards, environmental pathogens, pesticides, drug residues and natural toxins, to name a few. 
Considerations must also include hazards that occur naturally, those that may be introduced into our operations unintentionally, as well as those introduced intentionally."

\section{Recalls: Voluntary or Mandatory?}

You might hear that a company has been ordered to recall a product. For many years, federal regulatory agencies could not "order" recalls, except in the case of infant formula that had been adulterated or misbranded. This has changed with the FDA's increased authority under FSMA, as previously noted.

While most recalls are voluntary, it is usually in the best interest of a food facility to fully cooperate and initiate a recall when requested. Federal agencies can and will take quicker and more decisive action when a product poses a significant risk to human health if a manufacturer or distributor is unwilling to launch a voluntary recall, or if the agency decides the company's voluntary action is ineffective.

Before the FDA formally requests a recall, it usually already has evidence capable of supporting legal action. And even if a recall takes place-requested or voluntary-the FDA can still take legal action against the company at a later date.

21 CFR 7 contains the Enforcement Policy for "removing or correcting" food and drug products in the marketplace in violation of laws administered by the FDA, and it outlines the recall procedures to be used either by the FDA or FSIS. 21 CFR 7 is a thorough guideline for what can be expected in a potential recall situation. Here is a summary of what it says:

- Recall is a voluntary action, a way for manufacturers and distributors to carry out their responsibility to public health...from products that present a "risk of injury or gross deception or are otherwise defective."

- Recall is an alternative to FDA-initiated court action, and the FDA may undertake with or without a request to recall.

- An ad hoc FDA committee (Health Hazard Evaluation Committee) evaluates the potential danger presented by any product being considered for recall. The committee looks at things like whether any disease, injury, or death has already occurred, and what documentation exists to associate these occurrences withthe 
product.

- The committee looks at the label directions on the product and decides whether "any existing conditions could contribute to a clinical situation that could expose humans or animals to a health hazard." In short, was it used correctly, ormisused? Was it mislabeled?

- Was it a product malfunction? In the case of a food, was it an adulteration? In the case of a drug or cosmetic, was it an incorrect formulation? Was it a quality or packaging issue, like contamination (from glass, metal, plastic, non-harmful mold, etc.)? Was the product badly designed? All possible problems are taken into account.

- FDA assesses the product's potential impact on various segments of thepopulation (such as high-risk individuals: children, older adults, immunocompromised consumers, etc.); the "degree of seriousness" of the health hazard; and its actual likelihood of occurrence.

\section{Recall Classifications}

The committee also considers the short-term and long-term consequences of the potential hazard. Then, it assigns a classification to indicate the relative degree of danger:

A Class I recall means there is "a reasonable probability" that the use of the violative product will cause serious adverse health consequences or death. Examples: Product tampering or mislabeling of a lifesaving drug; foods that are found to contain the toxin causing botulism, foods contaminated with very pathogenic pathogens (including but not limited to Listeria monocytogenes, Salmonella or pathogenic E. coli); or a food that contains one of the eight (the Big-8) common allergens but is not properly labeled to indicate the presence of these allergens.

A Class II recall means the use of a violative product may cause temporary or medicallyreversible adverse health consequences, or the probability of serious adverse health consequences is remote. Examples: A drug that is below its labeled strength level, but is not used to treat life-threatening conditions; a diet product that contains more fat or calories than its label indicates and may be problematic for diabetics; a food that requires refrigeration but is not labeled with this precaution. 
Class III recalls are for products that violate FDA regulations but that are unlikely to cause adverse health consequences. Examples: Drugs that contain fewer tablets than are advertised on the label; a diet soft drink that is mistakenly labeled as a regular soft drink; a food that contains yeast or mold contamination or that may have been produced under unsanitary conditions.

21 CFR 7 also outlines steps for a recall strategy and lists these items as important in creating that strategy:

- The results of the health-hazard evaluation

- The ease (or difficulty) in identifying the product

- The degree to which the product's deficiency is obvious to the consumer or user

- The degree to which the product remains unused in the marketplace

- The continued availability of essential products

21 CFR 7 states that a company should do everything possible to put the recall into motion promptly-and not wait until the FDA reviews or approves its recall strategy. It says a recall strategy "will address" these topics:

- Depth of the Recall. Exactly who returns the products? How far (up or down)the distribution chain did the product go? Three possible options are noted:

o Wholesale level includes wholesalers and distributors, but not retailers.

o Retail level includes every distribution level except the consumer, both wholesale and retail.

o Consumer or user level involves the final consumer or user of the product.

FSIS recognizes an additional level, known as HRI-hotels, restaurants and other institutional-type customers and intermediate wholesalers that reach those users.

- Public Warnings. A public warning may or may not accompany a recall. How extensive should it be, and how quickly must it be launched? There aregeneral warnings in the news media (national, regional, local); others through the 
professional or trade press; still others to specific professions or population segments, like doctors, hospitals, schools, nursing homes, etc. When it analyzes a company's recall strategy, the FDA wants to see a "public warning and plan for distribution." A very recent warning released by the FDA, the "Public Warning and Notification of Recalls Under 21 CFR Part 7, Subpart C Guidance for Industry and FDA Staff (https://www.fda.gov/downloads/Safety/Recalls/ IndustryGuidance/UCM592851.pdf) explains this well.

- Effectiveness Checks. This is a way to measure how well the recall is working, whether everyone who was supposed to has received the proper notification, and how they acted on it. The FDA also rates levels of effectiveness as A through $E$, depending on what percentage of consignees is contacted about their participation in the recall.

o Level $\mathrm{A}$ is $100 \%$.

o Level $B$ is more than $10 \%$ but less than $100 \%$ of consignees.

o Level $\mathrm{C}$ is $10 \%$ of consignees.

o Level $D$ is $2 \%$ of consignees.

o Level $\mathrm{E}$ indicates no effectiveness checks.

The law says a company that performs a recall is responsible for checking its own effectiveness, but the FDA may step in and assist if asked.

\section{Agency-Requested Recalls}

The CFR covers agency-requested recalls in some detail. The Commissioner of Food and Drugs (or the commissioner's designee, usually an FDA Regional Office) may request a recall when the agency determines:

- A product presents a "risk of illness or injury or gross consumer deception."

- A company has not initiated its own recall of the products.

- An agency action is "necessary to protect the public health and welfare."

Notification may begin with a visit or phone call from an FDA regional office representative and is followed up with formal, written confirmation that specifies: 
- The violation.

- The health hazard classification (Class I, II, or III).

- A suggested recall strategy and any instructions for conducting the recall.

If a business does not want to wait for an FDA recall request, it can begin what the law terms a firm-initiated recall-that is, the company decides on its own to pull product off the market. The FDA considers voluntary actions as recalls only if the FDA decides the violation involved would otherwise be subject to legal action, such as a product seizure.

When you initiate your own recall, you still must notify the Reportable Food Registry. The information to have on hand, for this or in dealing with local or federal authorities, is:

- The identity of the product, including all brand names and container sizes.

- Copies of all pertinent labels.

- Lot numbers, serial numbers, any type of identifying code number.

- The reason for removal or correction.

- The date and "circumstances under which the product deficiency (orpossible deficiency) was discovered."

- A description of how the evaluation of risk was made.

- The total amount of product produced.

- The time period in which it was produced.

- An estimate of how much product is in distribution.

- The number of direct accounts to which it is distributed, and possibly their names and/or contact information.

- A copy of your recall communication, whether or not it has already been issued.

- The proposed recall strategy.

- A contact person at your company who is familiar with the situation and authorized to speak with FDA and other health officials. 
When the FDA gets these details, it reviews them, decides on a recall classification (Class I, II or III), and places the information in the weekly FDA Enforcement Report. The agency also offers advice about a recall strategy, if necessary. Finally, if a company thinks it might have a problem but the reason "is not obvious or clearly understood," the law says the FDA "will assist the firm in determining the nature of the problem."

This summary of food safety-related regulations will serve as a basis for the remainder of this manual, which will discuss the specific aspects related to food-recall activities. 


\section{Chapter Two: Before the Recall-Prevention and Planning}

The Food Safety Modernization Act (FSMA) mandates a preventive control plan for most food facilities. In other words, it isn't enough anymore to say that a facility solely relies on the HACCP system to ensure food safety. The FDA still wants to see in writing that a company has evaluated food-safety hazards; has specific steps ("controls") in place to prevent or significantly minimize them; can prove that it is monitoring to ensure the controls are working for identified hazards and that the company is keeping records of that monitoring activity; and can state specific actions the company will take if a problem arises. The specific actions are best described in a completed recall plan.

The FDA now has expanded authority to access these written records and greater enforcement powers to deal with companies that aren't following the rules or aren't working quickly enough to fix food-safety problems.

Taking preventive steps is how recall planning begins. This chapter focuses first on examining and evaluating your own manufacturing and distribution processes; then follows with advice on how to draft a product-retrieval plan that works for your company. 


\section{The Recall Team}

The most thorough recall plan means nothing without the right group of people trained to understand the nature of the suspected (or real) threat, and the knowledge and authority to carry out the plan. It takes a team to make a good plan - a team that is familiar with every aspect of your business, and perhaps a few outside experts who can be helpful in certain specialized areas.

The size of the recall team will vary depending on the business, and its responsibilities are to:

- Review existing operating procedures and recommend changes to lessen the probability of a recall, or to make a recall easier if it becomesnecessary.

- Develop a recall plan, or review and update an existing one to meet FSMA requirements.

- Respond to any product-safety problem that may require retrieval, includingall communications about the issue, internal and external.

- Make recommendations to senior management and any government agencies about what to do with remaining product.

- Follow through until the situation is resolved.

- Follow up by assessing the effectiveness of the plan and making suggestions to prevent similar incidents. 
Your recall team should consist of a core group of people who represent all the key departments or functions of the organization, with a defined leader of the group. The team should include:

- A senior operations manager who is familiar with the entire manufacturingprocess. This person typically serves as recall coordinator, the team leader who reports directly to the company owner and/or president.

- Your company's quality assurance director, another option for recall coordinator. Additionally, this individual is likely to be a PCQI. The PCQI is someone who has received training as outlined in the Preventive Controls for Human Food Rule.

- A public-relations or crisis communications specialist to coordinate communications activities. This includes media inquiries, updating your website and social media, getting photos of your products and labels, issuing news releases, etc. It isimportant to keep your messages clear and consistent, which is easier to do with a single point of contact.

- A marketing specialist to instruct the sales force (employees and independent sales contractors) in their dealings with customers and end users and to coordinate any marketing and advertising changes.

- A scientific advisor to address the health and food-safety aspects of the problem and help quantify the risks. This might be a food scientist, epidemiologist or microbiologist, depending on the type of pathogen and breadth of the problem or a toxicologist, in case the event is related to chemical contamination. You might need to select an outside lab in case independent testing is needed, preferably one with ISO 17025 accreditation. 
- A logistics and receiving specialist who is familiar with the shipping, tracking, and storage of products and can schedule timely retrieval from wholesalers, retailers, etc.

- A quality-assurance specialist who can start immediately to gather facts and then work with government inspectors to pinpoint any problem. This person should be familiar with all safety and sanitation rules of the company and able to arrange for laboratory testing of product samples. It is likely this person is a PCQI, aswell.

- An accountant to estimate costs of the options the team is discussing; set up account codes to track them; and manage a system for reimbursement (customer), if necessary.

- An attorney who can handle liability questions and help the team deal with government regulators. This person also can help the company collect pertinent oral and written statements; advise about what information may be kept confidential; and help you gather documents that may be needed as evidence in case of litigation.

If one person wears multiple hats on the list, your team will simply be that much smaller. Realize that you can't do it alone, and you may want to consider outsourcing. The public relations person, scientific advisor, toxicologist, and attorney all can be hired as outside contractors, as can laboratories to test for contaminants or pathogens. There also are companies that specialize in retrieving recalled merchandise.

When the employee members of the committee are in place, your first order of business can be to contact and interview outside experts. You will want to be acquainted with them, and they'll want to know more about your company, before they're ever needed. They should be prepared to make a short presentation to the committee about their services and prices. These outside experts could be under contract and "on the team" only during the recall planning process, if your budget allows this. 
Together, the team can create a sensible and workable recall plan that, with good management, good people, and a strictly maintained company culture of adherence to best management practices, your company may never have to use.

\section{Identification of Potential Problem Areas}

One way for your team to begin is to list the entire sequence of production (preferably incorporating accurate process flow diagrams) for the foods or beverages your company prepares. Then analyze every point in the sequence to identify potential weak spots. This is known as a hazard analysis and is a critical requirement of both the PCHF rule and HACCP.

Some companies draft a completely separate food defense plan, aimed at protecting products and processes from intentional contamination. Your food defense plan requires you to think like the bad guys, or perhaps a mystery writer-if you wanted to shut a company down, or cause it confusion or financial woes, how would you go about it? If an angry customer or disgruntled former employee decided to target you, your customers, or your consumers, what might they try?

In addition to a formal hazard analysis, it is often useful to look at your operation from a different perspective, namely dividing every activity in your company's operations into four broad categories-products, processes, people and property-and identifying potential problem spots accordingly. You can brainstorm as a recall team, but it is smarter to enlist the help of your department heads or a few trusted employees in this task.

We'll get you started with a list of possible areas of concern. There certainly will be others, depending on the type and size of your operation.

\section{Products}

- If your products are freshness-dated, is there a standard procedure for stock rotation-in your warehouse, and in the field? Do your customers know and understand it? Do they followit?

- Take a look at all your labeling with a critical eye. Could ingredients be listed in terms that would be more easily understood? In your zeal to market the product, have you used any terms or made any claims that are not allowed according to the Nutrition 
Labeling and Education Act (NLEA) or any updated labeling requirements?

- What kinds of laboratory testing do your quality control people do, and how secure are those records? How easy would it be for someone to falsify them-either to cover up a problem, or create one as a hoax?

- What food-safety and storage precautions are required at your facility? Are these in writing, and easily accessible to employees? Who monitors them to make certain they are being adhered to-and what are the consequences if they are not?

- If a disgruntled individual or terrorist group targeted one of your suppliers, vendors or shippers, how would it affect your operation? Are you aware of weak spots at your vendors' or shippers' locations? Ask if they have their own recall plans inplace.

- If chemicals or pesticides are used in any of your processes, get the most current safety information about them. Have activist groups targeted any of them for boycotts or other protests? Are the finished products tested for chemical residue, and are these records current and accurate?

\section{Processes}

- How do you approve vendors and suppliers, incorporating information about Supply Chain Preventive Controls programs where required (https://www.fda.gov/downloads/ Food/GuidanceRegulation/FSMA/UCM461834.pdf )? How do you check their products for safety, sanitation, etc.?

- Is there an inspection process for incoming raw materials and supplies? How does the receiving staff document incoming shipments, and how do they handle discrepancies? Is there a method for refusing goods? For accepting goods thatother users have sent back to you?

- What is your lot coding strategy? Do you have "clean breaks" in your product production? Do you use the suppliers' lot codes for incoming goods or assign your own new codes? Do you assign the same code to an entire shipment, or break itinto smaller increments? Does your system correlate the codes in case a supplier notifies you of a recall? You must be able to: 
o Link all raw ingredients to their original suppliers.

o Link raw ingredient codes to finished product codes.

o Code finished products by lot.

o Link finished product codes to wholesale or retail customers who receive the product.

- Do you have a system in place to clearly mark the code numbers on all outgoing product, and how is the product tracked when it leaves your facility? Experts say it is easier to track product when:

o The shipping cartons and individual containers inside them bear the samecode numbers.

o Only one code is packed in each case.

o Code numbers are changed often, making lot sizes fairly small.

- If your plant premixes raw ingredients for future use, are they coded to allow you to trace the individual ingredients in a batch?

- If you rework (use leftover product from one batch in another), do you codethe finished product to be able to trace the "leftover" ingredients?

- If chemicals or pesticides are used, how are they inventoried and stored? When do they expire? How are they disposed of?

- How are outgoing cases or shipments sealed or locked to prevent tampering?

- Examine how each process is documented. Are there gaps in recording the production, processing, or distribution history of a product? Who could change the records if they wanted to? Who has access to these records, and how is thataccess granted?

People

- Is there a standard form and/or operating procedure for receiving andhandling customer (e.g., retailer) and consumer (e.g., end user) complaints?

- What kinds of firewalls and virus protection does your computer system have? Is the system backed up regularly, and by whom? Who monitors online traffic? 
- Are criminal background checks conducted on all employment applicants? Drug tests?

- How are workers motivated to follow the rules? Do they truly understand theirown critical role(s) in creating safe products?

- Does every aspect of workers' training include not just how to do something, but why it is done this way?

- Do you have a badge, photo, or other identity-verification system for employees?

- How and where is mail sorted and delivered? Is there a protocol forhandling suspicious letters or packages?

- Is there a process in place for employees to report suspicious or unusual activity? Who investigates these reports?

- How are layoffs and terminations handled? How long does it take to close a terminated employee's file in the records and to restrict that person's access to the property, computers, and filed documents?

\section{Property}

- Identify points at which unauthorized persons might have easy access to yourfacility through unlocked doors, gates, loading docks, and vehicles.

- Think about whether any workers have unnecessary access to a critical part ofyour operation.

- Pinpoint any place and method by which a person might bring in, store, or move unauthorized materials within your facility.

- Do you have cameras onsite? Do they work? Who monitors them? How long are the videos stored?

- Is there emergency lighting in your facility? How well does it work and how often is it tested?

- Does your exterior lighting work to deter unauthorized activity?

- Does anyone inspect your water lines and analyze your water system for purity and access? If so, how often? How are discrepancies reported? 
A related topic for candid discussion among your recall committee members: To what extent might your company be someone's target? Does the company or industry-or its officers-have a lot of public visibility? Are they seen as controversial by any type of activist group? List all the outside interest groups, political parties, labor unions and trade associations your company and its officers are associated with. If you were in a crisis, would these groups be supportive? In short, it's time to think about who your allies are, as well as your detractors.

Another area that's difficult to quantify is how committed your workforce is to meeting quality standards and putting out the safest, most sanitary product. Examine what you are doing, or whether you could do more, to encourage the best quality standards. Company loyalty and ethics are tough to gauge, but it might be worth the effort to establish their importance and make employees aware that quality is an important goal.

\section{Risk Control and Insurance}

Now you should have a very thorough idea of what might happen accidentally or even intentionally, even if you make every effort to ensure that it never does. When you've identified these risks, you can decide how to reduce or eliminate them. Prioritize the list-as high, medium, or low risk-and tackle the highest risks first. You are looking for effective risk-control measures. An effective measure is one that reduces any of these three factors:

- The probability of a problem

- The severity of a problem

- Your company's exposure to a problem

Other considerations are the cost of the measure, and how it works (or conflicts with) other measures or day-to-day business processes-in other words, how expensive is it, and how much hassle is it?

As a very simple example, let's say your facility has an unlocked exterior door that provides easy access for anyone with a desire to sneak in. However, it is a local fire code 
requirement that the door be kept unlocked during business hours for safety reasons. You could:

- Make sure the area outside the door is well-lit to discourage entry.

- Install video surveillance and monitor the door.

- Post NO ENTRY signs and install an alarm on the door that goes off when itis opened.

- Put seals or sensors on the door that will show any attempt made to open it.

- Make sure the employee working nearest the door on every shift knows to keep an eye on it, with a small reward for reporting security breaches.

- Provide an outdoor break area, so employees won't be tempted to duck out this door.

As you can see, there are multiple options for risk controls, even for the simplest situations. Some methods cost more than others; some are arguably more effective than others. Whenever possible, employees who would be affected by the decision should be involved in making it.

\section{Recall Insurance}

Another critical part of risk management is insurance. Companies in many industries have recall-related insurance coverage. Now is the time to review your policy. Meet with your agent or broker, take a good look at exactly what the policy covers, and ensure that it meets your needs. If you're not very familiar with this type of coverage, type the words "product-recall insurance" on any Internet search engine and start reading. You'll learn from companies that want to sell it to you, from expert opinions in trade journals, and from attorneys' opinions about which types of insurance are worth the money and which are not. One of the most helpful sources is the International Risk Management Institute, found at

\section{https://www.irmi.com/.}

Almost all the major international food and beverage corporations have been through enormous recalls at one time or another, yet most of them are still in business. Many of these 
companies owe their survival to early foresight: they lined up appropriate insurance coverage before trouble struck, and they conducted the recall properly.

Four basic types of insurance cover product recall claims. Any of them can be purchased separately or added as an endorsement to an existing property insurance policy.

- A product-recall policy covers the actual costs of a recall: repairing and returning items, costs of publicizing the recall, transportation, and storage. Usually, this type of policy will not cover loss of profits or the cost of rebuilding a company's tarnished image.

- A product-liability policy protects the company against claims of injury caused by a defective or hazardous product. It is strictly to cover claims of injured parties, not recall costs.

- An accidental-contamination policy covers the company against claims resulting from its own unintentional distribution of an unsafe product. This includes all the related recall costs, and lost profits.

- Malicious-tampering insurance covers criminal actions of sabotage against a company and also includes all related recall costs and compensation for lostprofits.

Each of these is really a form of catastrophic insurance. If your recall team ever has to use its insurance coverage, it must be prepared to clearly document all of these expenses and losses:

- Cost of investigations - hiring private labs or outside experts

- Recall costs-for removal, transportation, storage, and destruction of the recalled products

- Repair or replacement costs - not just the cost of giving people new products but repairing any equipment that might have caused or contributed to theproblem

- Sales losses-not only the product that had to be recalled but the lingering effectsof negative publicity and the losses that will be incurred by the company'scustomers

- Legal and professional fees-attorneys, consultants, and accounting assistance to 
file the insurance claims

- Public relations costs-new advertising, special incentives, crisis management and anything else that is needed to get the recalled brand back in good standing with consumers after a recall

Attorneys warn that the basic Commercial General Liability (CGL) policies held by many companies are not sufficient to compensate for the massive costs that may be associated with a recall. Luckily, as with any other type of insurance, there are policies in many different price and coverage ranges. Premiums can range from $\$ 5,000$ to seven figures; deductibles from $\$ 10,000$ to $\$ 25$ million; for coverage from $\$ 10$ million to $\$ 300$ million or more. Most insurers have a tollfree hotline for companies to use in case of a product crisis; some offer their own expert consulting services at no additional cost to the policyholder. It is worth shopping around.

\section{The Decision to Recall}

When a recall is possible, the team's first goal is to assess the situation and make the first major decisions: whether to conduct a recall, and exactly which products are involved. Whatever the decisions, they must be supported by documentation.

If the initial notification was from a buyer or regulatory agency, a decision not to recall must be reached by mutual agreement with that agency. This avoids the possibility of punitive action by the regulatory agency and greater liability for the company in the event the problem is serious.

Even when regulatory officials are telling you they have some serious concerns about one of your products, a recall notification will not necessarily immediately follow. Remember, the FDA and FSIS prefer that the action be voluntary. A responsible company will determine in advance, as much as possible, under what circumstances a recall will take place. A regulatory agency may not have been the source of the information in the first place-it may be problems that your own employees or consumer complaints have brought to your attention.

- A product should always be recalled if there is credible evidence that shows it has caused any illness, from suspected contamination or another unsafe condition(e.g., 
undeclared allergens). Other situations may require more discussion. No matter what the circumstances, the decision to recall must always be made quickly. When a complaint first comes to your attention, you should be able to pinpoint the source of the complaint or notification and confirm the credibility of that source. If the information comes from health inspectors or a federal agency, listen carefully to what they say. Take notes. You have the right to ask for and/or expect:

o Courteous treatment.

- An explanation of the process or findings that linked this productto particular problems or illnesses.

o A specific time period for the records they are requesting.

- A minimal number of individuals or agencies requesting the same information from you.

- Access to supervisors or managers of the agency if a fieldinvestigator cannot answer your questions.

o Copies of paperwork, including news releases, the agency's inspections, lab reports, etc.

Ask if the inspector or agency is making a specific recommendation to recall the product in question, or any other recommendations. You will usually receive these in writing soon after the initial telephone or personal contact. Tell them you will notify your recall team immediately before a decision is made, and then do so.

If the information comes from a member of the public who has called or written to make a complaint:

1. Get as much information as possible from the complainant. Create a form that prompts anyone taking the complaint to get these details (see Appendix 1-2 for sample form):

a. All contact information (phone, email, mailing address).

b. Exactly what they feel the problem is with the food (chemical taste, "off"odor, allergic reaction, foreign object in the food). 
c. Exact product details (name of product, size of package, code numbers, whether they still have any of it left-in that container, or others like it that are unopened).

d. Details of how the product was stored and handled after purchase.

e. Name and address of the store where the product was purchased, and date of purchase.

f. Date and time the product was consumed.

g. Amount of product that was consumed.

h. Has this person ever consumed this product before?

i. Did others consume it, too, and do they have the same complaint?

j. Names and ages of the people who are affected.

k. Symptoms in the order they appeared and approximate time they began.

I. Medical confirmation of an illness; name and contact information of the doctor.

m. Name and contact information of any other agency they may have contacted to report this incident.

Keep in mind that a consumer is not required to provide you (the manufacturer) with all this information or may not be able to do so. In some cases, the consumer chooses to provide information to others such as physicians, public health officials, or attorneys. Often those agencies will ask the consumer to fill out a food diary (such as the one presented in Appendix 13) to help identify the food product responsible for the illness. However, when a consumer contacts you with a complaint, use whatever information you have to begin (or continue) your own internal investigation and testing. In all cases address complaints in a timely and professional manner. For threats made by telephone about product tampering or other biosecurity issues, use a form such as that in Appendix 1-4 to document theincident.

The second big question, about what should be recalled, refers to exactly which product(s) are affected. The answer may be:

- Particular lots or batches

- Items made between certain production dates 
- Items made at a certain plant

- Items that contain a certain ingredient, often an allergen

- Products that have been mislabeled

- Items with faulty packaging

- Products that may be contaminated

How far these products traveled in the distribution chain after they were released from your facility is another important issue. Where are they now? In wholesalers' storerooms? On supermarket shelves? Being served in restaurants? In public school cafeterias? Can you find them locally, regionally, or around the nation? Gauging the depth and breadth of distribution will help guide the committee as it decides whether to begin a recall.

\section{Alternatives to a Recall}

A company's first reaction is usually to try to limit a recall to include as small an amount of product as possible to minimize disruption, financial losses, and negative publicity. Regulatory agencies will insist on scientifically valid reasons for this kind of limitation, so be ready to justify your decision, whatever it is. Of course, there are other options short of a recall. They are:

A correction is an action taken to modify a product so that it may remain in distribution. Corrective action includes repairing, re-labeling, or making an adjustment to a product. With agency approval, a product might even be destroyed under the "correction" banner.

Product withdrawal (or market withdrawal), is the act of removing a product from distribution when it violates federal or state law in a minor or technical way (not posing a health-related risk), or when it doesn't meet the manufacturer's own specifications or quality standards. This does not include products that have been contaminated or adulterated.

In a withdrawal, you can notify your consignees (usually wholesale distributors and retailers) to remove certain products from distribution and replace them with new stock that you provide. You can have your own sales force or sales brokers perform the removal and replacement duties.

Stock recovery is removing a product that has not yet left the direct control of the manufacturer-it may be in your own warehouse, or on wholesalers' shelves, but has not been 
released to the public. Your company simply places a hold on the merchandise, so it does not leave your direct control.

Recalls can also be overseen by USDA FSIS for animal foods and USDA Food and Nutrition Service (FSS) for school lunch and other programs. More information on management of those recalls can be found here http://www.fns.usda.gov/sites/default/files/foodsafetyschools infographic.pdf.

\section{Create a Recall Plan}

After this initial information gathering and assessment period, it's time for the team or committee to draft a recall plan. Even if you are convinced that you will be able to use one of the other methods short of recall, it is necessary to have a written plan for several reasons:

- It is required under FSMA (for FDA-regulated foods where hazards are identified as requiring preventive controls).

- You might actually need it someday.

- When you do need it, the regulatory officials are going to ask to see it.

What should be in a recall plan? It does not have to be a long and complicated document to serve as a good blueprint for crisis management. Each recall plan will be different, of course, but many of the same major components are common to most. Consider the following suggestions compiled from the plans and documentation of many well-respected state health departments and university food safety experts.

\section{A Log of Your Actions}

One of the most critical steps is that the recall team maintains a written log of dates and times of any related event or action. This means logging when the complaint was received, when the team met, when the initial risk was evaluated, when testing was done, when production was stopped, when and how wholesalers were notified, etc.

Documenting your actions can help prove your responsiveness and promptness if later legal battles ensue. One person on the crisis team should be responsible for taking notes at all 
recall team meetings and keeping this log updated (A sample Product Recall Checklist that can form the basis of the recall plan can be found in the Appendix 1-5).

\section{A Decision Tree or List for Determining Product Emergencies}

Make a logical list, based on your industry and products, of questions you must answer to determine whether the emergency is a health problem or a hoax and, in either case, what should be done about it. The goal of your decision tree is to answer the two primary questions: Should there be a recall in the first place? If so, exactly what should be recalled?

\section{A Master List of Contact Information}

All the recall team members' names, phone numbers and email addresses must be listed, including a backup person in each role. You need to be able to reach these folks any time, day or night, if needed. If your company employs a PCQI, you should also have a backup if this person is unavailable, especially if this person is an outside consultant. A crisis rarely happens at a convenient time; be prepared in case you hear about a problem on a Friday afternoon at 4:40pm while most of your team is on annual leave.

As a part of the master list, compile a list of regulatory contacts as a separate section, including local health department representatives, police departments (in case of a threat or hoax), and the FDA District Office assigned to each of your processing operations.

In addition, compile a section of outside experts you can call on if needed: attorneys, crisis-management firm, insurance carriers, food scientists and/or laboratories for product testing, trade associations, call centers (for answering a high volume of calls), and trucking or logistics companies (for product retrieval).

A critical database is the contact information for your suppliers and their recall coordinators. List your sales representatives, who might be called on at short notice to contact your wholesale and retail customers. Make sure your sales team keeps the customer list updated. In short, find out who coordinates recall actions for each company you work with or to whom you sell. Don't let these lists languish over time. Keep them current. At a minimum, update them annually. 


\section{General Document-Handling Practices}

Documents relating to a recalled product should be gathered at the same time interviews and other elements of the investigation are being conducted. These documents may help explain how it became necessary to recall the product-and they may be requested by government agencies or litigants. Having them quickly available demonstrates that a company is wellorganized and cooperative.

No company documents should ever be destroyed before company officers and attorneys have determined whether it is legal to do so. More importantly, no recall-related documents should be destroyed under any circumstances after a recall has been initiated.

\section{A Method for Rounding Up Records}

The plan must include ways of accessing the following information within a few hours' time:

- Any routine monitoring or testing records that may pinpoint causes of a problemequipment servicing or breakdown, deviations on a processing line, failure to maintain HACCP or Preventive Control temperatures, or acidity levels of canned foods, etc.

- Production (period) codes, lot numbers, production dates (and instructions for locating and deciphering these codes on packaging), and label information for products in question.

- Receipts or other receiving documents for any raw materials used to make the product. (Remember, these also are important in case your company is notified ofa potential problem by one of your suppliers.)

- The amount of product potentially affected.

- Warehouse and distribution records for the finished product to track its current locations. 


\section{A List of Basic Regulatory Requirements}

If you notify the FDA or FSIS that you intend to undertake a recall, the agency will ask you to supply the following information. In your plan, state clearly whose responsibility it is to collect each of these details:

- The identity of the product, including original labels and use-by dates, the package size(s), product forms, codes, lot numbers, and any other identifying data. Photos of packaging and labels are helpful.

- The reason for the removal or correction and the date and circumstancesunder which the problem was discovered.

- An evaluation of the risk associated with the problem.

- The time span during which the product was produced and how much productwas produced.

- The total amount of product (by package size and case size) estimated to bein distribution channels.

- Distribution information - the number of direct accounts (brokers and wholesalers). In some cases, you'll be asked for their names, addresses and phonenumbers.

- A copy of whatever communication you have sent, or will send, about therecall. (See sample news releases and notifications in the appendices.)

- Your proposed strategy for conducting the recall, including measures tocorrect the problem and what you intend to do with the recalled product.

- The name and phone number of a contact person at your company that theagency can call to discuss the recall. (If you are not a manufacturer but are recalling a manufacturer's product that you sell or use, you must also supply contact information for the manufacturer.)

- It is advisable to add a sentence in the written recall plan that the plan itself is not an admission of any kind of guilt or negligence. Your attorney can help word this statement correctly. 


\section{A Method for Securing Product}

It is not sufficient to simply say that the items on this checklist will be done. Your plan must detail how they're going to be done, with time estimates for how long each step will take. At a minimum, the recall team must:

- Notify all department heads, who in turn notify their employees. (A list of department heads will be helpful here.) It is important to keep employeesinformed of company actions and their intent to effectively handle the recall.

- Stop production immediately pending an analysis of the causes of anysuspected problem.

- Immediately stop outgoing shipments of all products being recalled, even if the production dates are different than those under investigation.

- Notify all locations where the product may be to explain the situation and secure all product in warehouses or wholesaler/retailers' stockrooms. (The current list of customers and wholesalers will be helpful here.)

- Identify specific warehousing areas where affected products will be gathered.

\section{Drafts of Communication Documents}

As facts are determined, the recall plan must specify who should be contacted and what information should be dispersed. This includes employees, consignees, state and federal authorities, the news media, and the company's communications team.

To ensure that a consistent message is being delivered, it is absolutely critical that the team designates a single spokesperson to handle inquiries from the press and the public. Your attorney should brief this person before speaking publicly, so that your spokesperson does not inadvertently say anything that might later turn out to be legally damaging.

With so much to disseminate and so little time, it is smart to have templates ready that can be easily adapted to the circumstances. Your public-relations or crisis-management firm can be helpful in creating these. Ask your attorney to read all draft documents before they are used. You might need: 
- A form for documenting complaints and/or threats that come in by phone.

- A telephone script for calling consignees (distributors, wholesalers, retailers) to inform them of the recall.

- An email or fax message (to precede or follow) the initial phone call toconsignees, confirming the recall information.

- A letter on company letterhead, restating the recall information and providing specific details for the destruction or return of the product.

- A news release to provide to news media and to post on your website.

- A recall effectiveness check, which can be done by letter, by phone, or in person.

- A recall status report, which the FDA or FSIS will want to see. It is a written update of progress during a recall. (See Chapter 3 "The Recall Begins: Investigation and Cooperation" under the section called "Monitoring a Recall" for details on what it must contain.)

\section{Test the Recall Plan}

A mock recall is an excellent way to test your plan and your company's response time. How quickly can your team identify and segregate a specific product and disburse information to those who might be affected by selling or consuming the product?

For the test, select product from your actual production records. It should have real-life period codes, lot numbers and production dates. Pick at least one lot that was recently produced-some stock is still on-site or in storage, and some is already out in the marketplace. This allows you to check internal as well as external ability to account for the product. The test will only be effective if you also set timed goals.

The recall team should convene and initiate the exercise. In all communication, however, be sure to stress the fact that this is a mock exercise designed strictly for emergency preparedness and that nothing is wrong with the actual product.

The mock recall should involve a complete review of your company records and, to a certain extent, external sources of information such as shipping and the receiving company's records. Brief the employees and perhaps offer an incentive for meeting the research 
deadlines. Ask your brokers, distributors, and retailers to participate, and let them know they are being timed to see how quickly they can locate the product and report back to your sales force. Consider giving them a discount on their next order of that product for helping with the test.

Mock recalls are "mini" versions of real ones. They're supposed to take two or three days, not weeks or months to complete. Therefore, progress should be assessed every few hours.

Some production facilities run exercises similar to a mock recall but not as extensive. They practice tracking every bit of their inventory within a two-hour period, to see how accurately they can pinpoint locations, code numbers and quantities in case of a recall situation.

The most important part of a mock recall is the debriefing session at the end. The entire point of the exercise is to prove that the company can effectively trace all raw materials through receiving, production, packaging, and storage, and that it can determine the locations to which all product has been shipped. Testing the plan will quickly point out any shortcomings, which can then be revised to work better in case of a real emergency.

The date and results of each mock recall or product-tracking exercise should be documented in writing. If you modified your recall plan based on the results, this should also be noted. 


\section{Chapter 3: The Recall Begins: Investigation and Cooperation}

The hard work that has gone into your company's recall plan is put to the test when a problem is called to your attention. A solid plan divides the responsibilities among people who best know how to carry them out, outlines procedures for collecting the right information as quickly as possible, and requires that every step be documented in order to avoid duplicating efforts and to justify your decisions if asked for details by regulators.

An owner or senior manager should already have instructed the team to compile all necessary records to investigate the cause or source of the concern, if it isn't the result of a supplier's problem. Even if a supplier issue causes the problem, you will have to assemble all the relevant records.

Remember, in some cases you will have only hours to do this - at best, you'll have a couple of days. As mentioned in Chapter One, the first question was, "Should there be a recall?" If the answer was "yes," the next step is to determine exactly what should be recalled. Therefore, you are looking for evidence of:

- The credibility of the complaint(s) or allegation(s). This generally isn't an issue if the problem has been called to your attention by a supplier or an agency, such as the CDC, the FDA, or your state health department. But customer complaints that come directly to your business will require additional scrutiny.

- The problem and product.

- The degree of actual public health or safety risk.

- Possible cause(s) of the problem-or circumstances that make people assume there is a problem when it may not be (i.e., mold that occurs naturally on some foods but is harmless, etc.).

\section{Gathering Evidence}

Where do you begin? Think like a lawyer. In addition to specifics about the nature of the problem and the possible cause, you want to compile evidence that your company is doing a 
good job, even as you search for weak spots. And never, ever discard records during this process.

First, do not overlook internal email communication. This may mean alerting your Information Technology department to maintain an archive of the email accounts of those employees who are closely involved in the case. (Ask your attorney about this step, which is primarily for your own internal investigation.) There are many other potential sources of information and data:

- External sources: Brokers and distributors; health inspectors or other regulatory agencies; news reports or social media; suppliers (or ingredients and/orpackaging materials).

- Your own company records: Complaint history or complaint log; quality assurance data (lab test results, internal inspections); production data (equipment maintenance logs, date coding, product or packaging specifications); distributionand storage data; discussions with employees.

- In a larger company, the tasks may be spread out over several areas and responsibilities can be assigned by department. In a medium- to large-sized company, the division of duties and tasks might look like this in the early stages of a recall:

Recall Coordinator-Convene and chair meetings of the recall team. Serve as liaison between the company and regulatory agencies. Keep current records of all regulatory agencies' contact names and numbers, and all copies of information (both sent and received) pertaining to the product investigation and recall plan. Be readily available to meet and/or communicate with regulatory officials.

Accounting-Set up new account codes to keep track of expenses related to the recall and, ultimately, assess its financial impact. Confirm the status and limitations of any insurance coverage. Set up standard methods of processing refunds or crediting accounts for returned product. Work with sales and consumer affairs to make them aware of these actions. 
Consumer Affairs-Brief anyone who answers the phones about what to say to callers. Arrange for additional telephone staff, an outside call center or a toll-free hotline if many calls and inquiries are expected. (Use the sample form in Appendix $X$ to organize information from callers.) If incoming calls are forwarded to others, create procedures for who receives which type of call. Work with the public relations department to determine what information will be released to consumers, or to customers who call to find out what to do with the product they have on hand. This may include product segregation and clear labeling to represent that the product is on hold and not to be distributed for sale. Present your findings and suggestions to the recall team.

Distribution - Locate and immediately stop all shipments of the product, and arrange for their return to specific collection points. List all inventory and where and when it was distributed. Identify, separate, and clearly mark any of the product that is still on site. Check storage conditions in company warehouses and delivery vehicles. Start a "recall log" to keep track of product as it is returned to the company. Present your findings and suggestions to the recall team.

Legal-Look at specific complaints or allegations in relation to the laws that impact the recall. Check the wording of any outgoing letters, prepared statements or news releases. Advise the company officers and recall team on correct handling of consumer complaints and how to respond to any threat of litigation. Sit in on discussions with regulatory officials. Assist in interviewing employees for evidence-gathering.

Production-If your business is a manufacturing plant, gather all records for the product in question-production, equipment maintenance, safety, and quality assurance. Stop production, if necessary. Assemble records and provide written explanation of any product codes and complete sets of labels. Work with distribution to locate all the inventory in question. Report on the shelf life of any product that has already been shipped. Present your findings and suggestions to the recall team.

Public Relations-Designate a spokesperson to be the company's "public face" and/or hire a crisis communication professional. Immediately begin monitoring the company's social media accounts. Write fact-based statements to share with employees and shareholders along with news releases and/or website and social-media updates. Write communications to notify customers. Create a script for taking complaints or questions by phone or any other communication stream. Today you're just as likely to get 
complaints/questions by Twitter or Facebook or other social media, and you should have a script/plan to have those regularly monitored and addressed. Work with sales staff to prepare handouts and point-ofsale information for retail customers to help them communicate with their own customers. Work with legal counsel, and perhaps the regulatory agency involved, to approve these documents and/or prepare to speak with reporters. Keep the recall team regularly updated.

Quality Assurance-Oversee the technical investigation of the problem. Obtain and examine samples of the product in question and contact outside experts or laboratories for assistance if necessary. Be able to provide and interpret process flow charts for products and have all your foodsafety process verification documentation/methods ready for discussion. Provide technical information and test results to regulatory authorities. Maintain a list of possible experts to contact to help determine the hazard level. Present your findings and suggestions to the recall team.

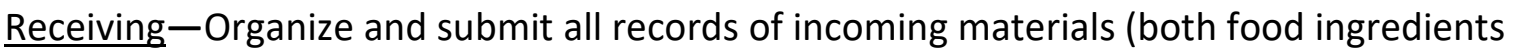
and packaging) and inspections of each. Compile or update a list of growers and suppliers who ship raw materials (including packaging materials) to you, in case one of their products ends up being part of the recall.

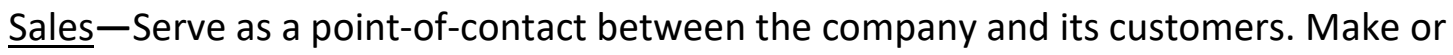
update lists of contact information for accounts that may have custody of the product. Present your findings and suggestions to the recall team. Later, help customers remove the product from sales and isolate it for its disposition. Distribute any written explanation of the situation to them-letters, flyers, posters, or point-of-sale materials. Refrain from speculating about the reasons for the recall. Instead, reassure customers and keep them informed about financial adjustments, credits, or new product stock they may be offered.

It is critical to brief each department within your organization about its specific responsibilities and give department managers deadlines to meet for their recall-related activities. As you might imagine, many if not all of these activities are taking place at once. It is 
important to realize and acknowledge the impact that a recall has on many employees.

\section{Analyzing the Evidence}

The recall team's next job is to compare the complaints and the evidence that has been collected to the pertinent laws. It may mean poring over FDA or FSIS standards or city or county health, safety, or sanitation codes. It may require assistance from outside experts. The goal here is to evaluate the seriousness of the allegations-to learn as much as possible about exactly what is being charged and how you can disprove the complaint, offer a reasonable explanation for it, or acknowledge a problem and fix it.

Unless an FDA- or FSIS-initiated recall is already being requested, the only way to decide on a company-initiated recall is to analyze evidence and compare it to the applicable laws. Your attorney should be especially helpful in this step, as well as outside experts who may be valuable in determining the hazard level.

One benefit of FSMA is that food-processing companies are required to validate and/or verify that the preventive controls they've put in place are effective and implemented consistently. In the case of a potential recall or other emergency, these verification processes could make it easier for you to pinpoint and/or rule out problems like equipment malfunction, inaccurate instrument calibration, or a breakdown in your monitoring system.

This is also the point at which you may want to obtain independent laboratory analysis of product samples, even if you already routinely analyze the product in-house. Remember, however, that once a regulatory agency determines (as the result of their laboratory analysis) that a product is adulterated, that finding stands-no matter how many results to the contrary are submitted by your company or your designated independent lab. The agency can be expected to always take the most cautious approach.

If it is a company-initiated recall, the FDA (most appropriately the FDA District Recall Coordinator) and any other appropriate agencies should be notified. The team spokesperson (with the attorney's review) should prepare this notification and attendant supporting information. Agency-initiated recalls are rare but require collection of the same general information as with voluntary recalls (https://www.fda.gov/Safety/Recalls/IndustryGuidance/ucm129259.htm). 


\section{Announcing a Recall Action}

"To stem the tide of litigation, the food industry could do a much better job at internal and external communications," said attorney Ronald J. Levine of the East Coast law firm Herrick, Feinstein LLP, in an article in Food Safety magazine (http://www.foodsafetymagazine.com/ enewsletter/the-four-commandments-of-food-litigation/). Indeed, nothing will test your communications prowess as thoroughly as a product recall. Let's look at what the law says as well as what the regulatory agency will send out to you regarding what you must do to communicate recall information to your customers.

\section{The FDA's Communication to the Public}

The FDA's regional office immediately sends a "24-Hour Alert to Recall Situation" notice to the appropriate central FDA department (biologics, cosmetics, drugs, devices, foods, or veterinary medicine). This bulletin summarizes the reason for the recall, the product, and the company initiating the recall.

The official news releases can vary in terms of information provided. There's a very specific, boilerplate format for each of these notices, and you can find examples on FDA's website: https://www.fda.gov/Safety/Recalls/IndustryGuidance/

The FDA also notifies public health authorities in the state(s) in which you do business. Internally, agency personnel use an electronic database known as the Recall Enterprise System (RES) to input information about each recall to help them track it to completion.

The FDA's website for communicating recalls, market withdrawals and safety alerts is http://www.fda.gov/Safety/Recalls/default.htm. Most are called “Company Announcements" and include photos of product packaging, labels, etc.

The FDA puts recall information in its Weekly Digest Bulletin, emailed to anyone who requests it. Links in the bulletin lead to the same company announcements on the website. Information also is disseminated through Twitter (https://twitter.com/FDArecalls or by following @FDArecalls through a Twitter account).

The USDA's FSIS team puts similar product-recall news releases online, at http://www.fsis.usda.gov/wps/portal/fsis/home. The FSIS Twitter site is 
https://twitter.com/usdafoodsafety; interested parties can also track USDA FSIS-related recalls by following @usdafoodsafety).

Remember, news reporters are among those who sign up for these mailing lists and RSS feeds. You might very well see a mention of your recall in an online publication such as Food Safety News, or the wide-ranging list of recalled products posted on the consumer watchdog website WeMakeltSafer.com.

\section{Your Communication to Customers and Suppliers}

In an agency-requested recall event, a recall coordinator in the regional FDA office must approve any communication you send out as a company regarding the recall-to your customers and suppliers, and to the general public.

If your company makes its own decision to recall, 21 CFR 7.42 says the FDA, "in consultation with the recalling firm, will ordinarily issue such publicity." The same portion of the law "requests that the proposed public warning and recall plan be submitted to the FDA for

review and comment." You will almost certainly be collaborating with the agency to publicize the recall.

The law says your communication must accurately reflect the level of danger that may be involved in using the product, as well as the strategy developed for the recall. 21 CFR 7.49 suggests being "brief and to the point." By law, the recall communication must include these details:

- The complete identity of the product, along with labels, brand name, code number, and other identifying information.

- That the product is being recalled.

- That "further distribution or use of any remaining product shouldcease immediately."

- That this customer should notify any of its own customers if they receivedthe product.

- Specific instructions for what to do with the product. 
The 21 CFR 7.42 also states that recall information can be disseminated by "...telegrams, mailgrams, or first-class letters conspicuously marked, preferably in bold red type, on both letter and envelope: drug [food or biologic, etc.] recall [or correction]". The letter or envelop used should be marked as "urgent" for class I and class II recalls and, class III recalls if appropriate. If reported by telephone or by personal contacts, these also should be confirmed by one of the above methods and/or documented in an appropriate manner.

Recall communication should also include a "ready means" for the customer to report back to the company and should stress that even if the customer doesn't have any of the product on hand, the customer should still respond. The FDA's suggestions are:

- A self-addressed, postage-paid postcard, or

- A phone number for customers to call, collect or toll-free.

Many consumers prefer electronic communications, so it's worth checking with your regional FDA office to see if email communication might suffice in some cases. This is another good reason to keep your customer electronic address database updated. As noted, it's a good idea to stay updated on FDA's current information regarding recalls by regularly reviewing the information found at http://www.fda.gov/Safety/Recalls/default.htm.

When recall details are given by phone, make sure your company representative has a written script to work from to ensure everyone is given the same details. If recall information is given to customers in person or by phone, the FDA says the recall information should still be sent in written form, as well.

The law also notes that the recall communications "should not contain irrelevant qualifications, promotional materials, or any other statement that may detract from the message." Finally, this section of the law states that the recipient's responsibility should be made clear to them-exactly what is expected of them and how important it is to immediately carry out the recall instructions and notify other people in the distribution chain, as necessary. Remember, by following the law, you are also helping defend yourself against the possibility of private lawsuits resulting from the recalled product. 


\section{Your Communication to the Public}

Good crisis communication will make the difference between a recall that causes some shortterm disruption and one that puts the company out of business because of negative publicity.

Remember what the FDA or FSIS is now deciding: the depth of recall, the extent of public warnings that will be required, and what level of effectiveness checks will be required. Each of these decisions affects the types and quantity of information you will have to write and release.

When a product emergency or recall action is in its initial stages, certain steps must be taken as soon as possible. They are:

- Decide who the audience is that needs information immediately. There isalmost certainly more than one group, and their information needs will be different. These might include incoming callers, your workforce, your shareholders, government agencies, growers, suppliers, wholesalers, distributors, retailers, specific industries that use your product, news media (including the trade press), and the general public.

- Decide on a spokesperson for each of these audiences. Your sales team might be the appropriate group for contacting distributors and retailers, and department heads can speak with your workforce, but it is usually best to select a single spokesperson-"one voice, one face"-for public communication.

- Decide the quickest, most effective way to impart this information: an afternoon of personal phone calls? A news conference? A tweet or an email blast? A mandatory meeting at each of your facilities? Document each contact in writing, no matter how it is made. Be sure to include the date and the author of thecommunication.

- Make a simple statement that says your company is aware of the situation, is investigating further, and will provide more details as soon as they are known. (This is sometimes aptly referred to as the "we're aware and we care" statement)

- Give as much detail as you can about the nature or extent of the problem and any actions that are being taken, but focus on the key points. Don't get bogged down in minute or scientific details that the reader or listener won't understand -or that 
cause undue alarm.

- Limit your remarks to only what you know to be true. If you don't know something, it is best to say you don't have the answer yet. Do not speculate, and keep your temper in check even if you feel some of the endless questions seem like you're being badgered or baited. Professional training in handling inquiries under high-stress circumstances is invaluable to those that expect to handle inquiries. It cannot be overstated that it is important to address the regulators, press, customers, and consumers in a calm, honest and professional manner.

- Your website and Facebook page are among the first places today's customer (or news reporter) will look for information. See that they are updated immediately as new information becomes available to reflect the latest progress or developments in crisis situations. This is particularly helpful because you can refer clients and callers to these pages for updates and instructions. Maintain a record of update details.

- Keep a log of who calls or emails questions, and document what you've told, sent or given them.

Standing outside your facility repeating "No comment" into cameras and microphones can make you sound less than cooperative. Consider calling the media yourself instead of waiting for them call you. There is nothing wrong with contacting local journalists proactively with a concise statement and background materials to offer.

Keep as much of the communication in writing as possible, and deliver it through a single spokesperson to help ensure that your message is consistent and clear. When the situation calls for some technical explanation, back up your spokesperson with an expert or two if necessary, letting them handle questions in tandem. Rely on your quality assurance department to select the experts who are most familiar with your operation.

The recall team should also meet with senior management, sales, and accounting to decide how best to replace the recalled product and compensate customers for the inconvenience, as well as the physical loss of inventory. The sales team's job is even more difficult in a recall situation, and freeing your team to offer meaningful goodwill gestures and collateral materials to customers is an important step toward maintaining or rebuilding your 
company's credibility.

During a recall or other type of product emergency, it is hard to see that anything good might come of it. But if you manage to deal honorably with-and gain the trust of-news reporters, business associates, customers, and members of the public, you may actually benefit long term from a difficult situation.

\section{Monitoring the Recall}

The FDA or FSIS approves or modifies the company's recall plan, and the product recall is underway. Your recall team members are tending to their responsibilities-and so is the agency watching your progress. For Class I and II recalls, the government agency will call or visit some of your customers at random, just to be sure they've been notified and are taking appropriate action.

The law is clear: "It is the recalling firm's responsibility to determine whether its recall is progressing satisfactorily." Your company is the recalling firm. You have done your best to notify customers and clients and inform them about what's wrong and what they should do with the product after removing it from their inventory.

Consider for a moment, however, all the potential risks along that path. Even well into the recall process, the recall team must continue to ask: Is there anything more we could or should be doing? And is every step being documented as thoroughly as possible?

\section{Recall Status Reports}

The recalling firm must submit recall status reports to the agency (usually the FDA District Office) at intervals of three or four weeks. (The agency decides the frequency.) Each report must contain the following information:

- Number of consignees contacted.

- Dates and methods used to notify them.

- Number who have responded to the recall contact, and

- How much product they had on hand at the time of notification.

- Quantity of product returned (or corrected) by each consignee who wascontacted. 
- Total quantity of product that has been accounted for thus far.

- Number of consignees who have not responded. (The FDA may request their identities and contact information.)

- Number and results of any Effectiveness Checks that have been made.

- Estimated time frame in which to complete the recall.

If the agency that reviews the recall status reports decides the recall is not proceeding quickly or smoothly enough, or that a significant quantity of the product remains on the market despite the manufacturer's efforts, the agency may move to legally detain or seize product unless the company is willing to take more effective action.

\section{Effectiveness Checks}

The FDA will also specify how many of the consignees to contact during the recall period to gauge the effectiveness of the recall. Effectiveness checks (also sometimes referred to as audit checks) verify that consignees have received their recall notifications and have taken the appropriate action. These follow-ups are done throughout the recall by phone, fax, mail, email, or personal visit (See a sample Effectiveness Check questionnaire forms at https://www.fda.gov/downloads/Safety/Recalls/IndustryGuidance/UCM214971.pdf. As you've already learned, Effectiveness Checks may be mandated for all the consignees (Level A) or as few as two percent of the consignees (Level D.) At Level E status, for extremely minor problems, they don't have to be done at all. You cannot suggest or change the level for your own recall-it is assigned by the FDA.

The FDA may entrust Effectiveness Checks to a state health department and ask the department to report its findings to them. Since your company is ultimately responsible for the success of the recall, you may also ask to see the results. Areas to be addressed for further improvement should be noted.

\section{Gauging Public Opinion}

Your communications staff will want to closely monitor Twitter, Facebook and anywhere online that customers can interact publicly with your company. In extremely serious or far-reaching 
cases that might involve news coverage in multiple cities or states, most major cities have "clipping services" that save newspaper and television reports and provide you with copies or summaries of the coverage for a fee-provided they know to look for it in advance. Find out more about the local clipping services before you need them.

If your company does not perform consumer opinion research, your public relations person should locate a market research firm to survey your consumers by phone, in person, or electronically. Consumer surveys can provide valuable feedback about what to do if it is necessary to rebuild customer trust. Some types of recall-related insurance cover these business-rebuilding expenses.

\section{Disposition of Product}

A 2003 report by the US GAO reported that fewer than 40 percent of recalled foods are ultimately recovered (http://www.gao.gov/new.items/d0551.pdf). In your own recall action, a primary goal should be to exceed that percentage.

When determining what to do with cases of product that are defective or suspect, the most important advice is to not destroy or dispose of any product without first:

- Submitting a written plan to the FDA, FSIS, or other regulatory agency about what to do with the product and getting their approval of this plan.

- Offering to have a state or federal agency representative there to witness whatever action you take.

In most cases, the manufacturer either asks that the products be returned or destroyed. This decision should be made based on whether they can be reconditioned or repackaged and sold safely. If reconditioning is an option, be aware that government supervision will probably be required.

In a limited recall involving only certain lots or product codes, make it clear to those who are selling the product at retail to only remove the items with those specific lots or codes. In a supermarket setting, for example, consumer confidence is far more likely to be negatively affected when they see a shelf completely empty. 


\section{Donation}

Sometimes, in the case of Class III recalls when the problem is related to labeling and the product does not pose any type of health risk, a company may be allowed to donate the recalled merchandise to nonprofit organizations. In this case, be sure the nonprofit group provides written documentation that it understands the recall terms and is still agreeing to accept the product.

\section{Reconditioning}

The question here is, is there any way to safely create value from the recalled product? If it is meat or poultry, before the product can even be transported to a reconditioning site, the recalling company must request permission from the FSIS District Manager and then notify the local USDA inspector of its arrival date at a USDA-inspected plant. When it arrives, the inspector checks the product to determine whether, and how, reconditioning can proceed-and may supervise the reconditioning process or at least re-inspect the reconditioned product before it can leave the plant again. Reconditioned product that still doesn't meet USDA standards is destroyed.

\section{Destruction}

If the product poses a potentially serious health hazard, the FDA or FSIS may require that it be gathered in a single location for destruction. The method of destruction has to comply with all regulations (local, state or federal) about disposal of toxic materials and/or landfill use. The recall team should compile a list of approved landfills and disposal services.

In serious cases, it's not enough to throw product away if it could be retrieved and consumed. The manufacturer must keep records of the code numbers and quantities destroyed. Get a receipt for whatever was paid to the landfill or other site, including the address and date and the method used for product destruction. It's a good idea to document the destruction process by photographing it or capturing it by video.

If a product is simply spoiled or rendered unsalable in some manner that does not pose a health hazard, the consignees may be asked to dispose of the product like any other waste, 
with their trash. Simply throwing recalled product away introduces an additional element of uncertainty into the recall effectiveness calculations, however, and thus it is not recommended. If for some reason consignees choose to dispose of recalled products, be sure to have each consignee document what they discarded, how much they discarded, and when they discarded it. Better yet, have your salesperson onsite to help with the task and document the disposal. 


\section{Chapter 4: After the Recall: Legal Liability and Rebuilding Trust}

In an article entitled "Damage Control (Scholz, 2009) the author states that several key attributes affect a company's reputation: trust, transparency, credibility, commitment, and honesty. Whether you are dealing with a federal agency, your workers, suppliers, or customers, those are the big-picture considerations as your company emerges from a recall situation.

\section{Ending the Recall}

It is important to note that the regulatory agency working with you during a recall is also under pressure to do its job well. The FDA, for instance, has its Regulatory Procedures Manual (RPM), which should be required reading for any company that produces food products. Here's the link: http://www.fda.gov/ICECI/ComplianceManuals/RegulatoryProceduresManual/ Chapter 7 of the RPM includes the FDA guidelines for reviewing a company's recall status reports promptly, monitoring the disposition of recalled products, and taking action if agency personnel believe a company isn't moving quickly enough or have decided the company's recall plan is ineffective.

There's also a process within the agency for wrapping up a recall, compiling and analyzing the Effectiveness Checks, and making a final determination that the company has sufficiently carried out its recall plan-or that it has not. Chapter 7 of the RPM doesn't go into much detail about how recalls are ended, likely because endings vary depending on the type of product, the breadth of distribution, and the nature of health or safety hazards. It says a product recall is considered officially complete when all reasonable efforts have been made to correct the violative product or remove it from commerce. The CFR (Title 21, Part 7, Section 7.55) puts it this way: “(a) A recall will be terminated when the Food and Drug Administration determines that all reasonable efforts have been made to remove or correct the product in accordance with the recall strategy, and when it is reasonable to assume that the product subject to the recall has been removed and proper disposition or correction has been made commensurate with the degree of hazard of the recalled product."

Ultimately, this is the decision of whatever federal agency is involved. The written recall termination will come from the FDA District Office handling your recall. 
The Recall Team Wrap-up

Even when a recall is over, a company's recall team still has a lot to do. The team should continue to meet to:

- Review the procedures and discuss how well the plan worked.

- Create a written report that details the entire recall.

- Collaborate with the appropriate departments within your facility if the problem was internal. Set a follow-up deadline to see that the changes you agreed upon have been made. Update food-safety plans to reflect any changes in hazard analysis, process controls, or other plan components.

- Decide what types of "wrap-up" communication are appropriate-to consumers, retailers, suppliers, agency personnel, employees, and the news media.

- Determine the ongoing fate of the product post-recall-Destroy it? Reformulate it? Repackage and reintroduce it?

- Discuss recall-related costs and file appropriate insurance claims along with documentation of expenses and losses.

- Follow up on any corrective actions taken to determine effectiveness.

- Consult with your attorney about the potential for litigation.

The oft-cited industry average for food-recall direct costs is $\$ 10$ million, which doesn't include litigation that might result from consumer deaths or illnesses. When determining costs, account for both direct and indirect expenses. Direct costs include notification of all parties, payment to third-party experts for laboratory testing, legal advice, equipment repairs, and so on. There are product-retrieval (storage and transportation) expenses, costs for destruction of the product, if necessary, and additional labor costs for the hours put in by frontline workers and recall team members.

Indirect costs include what the company is losing in being unable to sell the defective product and longer-term damage to your brand or reputation post-recall. In a 2014 Harris Interactive poll of more than 2,200 Americans about food safety, 55 percent said they would at 
least temporarily switch to another brand after a recall, and 33 percent said they would never again purchase a brand if it had been recalled due to health or safety concerns (http://www.theharrispoll.com/politics/Nearly Three-Quarters of Americans Looking to Government for More Food Safety Oversight.html). These most likely aren't people who will call your consumer hotline or send a letter or email message explaining their feelings. They'll simply pass up your products on the store shelves in favor of your competitors'. They might even remember just the basics—“Didn't I hear something about a peanut butter recall?"-and bypass the entire product category indefinitely, "just to be safe." All this creates nightmares for your marketing department and your bottom line.

\section{Product Liability Lawsuits}

Among the scariest terms in the English language for corporate executives is "pending litigation"-and yet, it is always a possibility in recall cases. One study indicates the average settlement amount for recall-related litigation is more than $\$ 200,000$.

If a lawsuit is filed by an individual in the company's home state, the laws of that state will apply. If, on the other hand, the product has been recalled nationally and people in other states file lawsuits, the company being sued may have some input about which state's laws will apply. This is important because state laws vary drastically on almost every important aspect of product liability cases, from statutes of limitation to plaintiffs' ability to collect punitive damages. As an example, let's use statutes of limitation. As of this writing (according to FindLaw.com) for a product liability claim in about half the states, consumers have two years from the date of illness or injury to file a lawsuit. However, it is one year in Kentucky or Louisiana, three years in 13 states, and four years in six states, including Florida. Only a few states have longer statutes of limitation, including five years in Missouri, six years in Maine and North Carolina, and ten years in North Dakota. Many states have enacted an additional statute of repose, meaning the legal action has to be brought within a certain time period after an event (such as a product sale) has occurred.

Another important difference is the type of claim the consumer can make. Here are some of the issues that consumers and their attorneys will be deciding: 
- Strict Liability or Negligence - In a strict liability case, the plaintiff does not have to prove that a company was negligent. Various states have mandated different tests for liability and/or negligence.

The "consumer expectations" test is a common-sense approach in which a product is considered defective if "any reasonable person" would expect it to be in a certain condition, and it is not achieving that condition.

The "risk-utility" test weighs the usefulness of the product against the risk it presents the consumer. A product fails the test if a reasonable person would think the risk outweighed the utility. Risk-utility is determined by factors like the seriousness of the problem use of the product could cause; the probability of the problem occurring; and whether the consumer took adequate precautions in using the product.

Proving negligence usually requires proving "proximate causation," that is, the problem was foreseeable by the food manufacturer. But again, different states have different definitions of causation.

- Punitive Damages - This is an amount of money added to a judgement or settlement to punish a company for wrongdoing. Some states allow it only when a wrongful death has occurred, and others don't allow punitive damages at all in product liability cases. A few states allow them depending on whether the plaintiff can prove the company showed "reckless disregard" for safety, or had "actual knowledge" of a dangerous condition and failed to act on it.

- Class Action Litigation or Lawsuit - When several (or hundreds) of people file similar complaints or lawsuits, your company may be faced with a class action lawsuit-one case that covers everyone who joins the class. Sometimes this is the quickest way to resolve a large case. It usually involves a one-time settlement amount and is less complicated than negotiating dozens of smaller suits in different states. 
A company may decide to oppose a class certification if it is convinced the claims are not valid, or if the settlements to each plaintiff would be so small that it's not worth litigation expenses. Your attorney can help you make the decision.

\section{Criminal Versus Civil Cases}

As attorney Bill Marler pointed out in a Sept. 9, 2015 article "Why the CEO and Board Need to Pay Attention to FSMA" published in Food Safety News (http://www.foodsafetynews.com/ 2015/09/why-the-ceo-and-board-need-to-pay-attention-to-fsma/\#.WbFzS62ZPUI), "There have been more criminal prosecutions in the past five years of food company managers than in the prior two decades combined. Hefty fines and jail time do have a way of focusing one's attention."

Because food-related illnesses can pose serious health outcomes, courts have ruled many times that a prosecutor does not have to prove that a company was aware of the problem in order to make a case. Ignorantia juris non excusat or "Ignorance is no excuse in the eyes of the law." In fact, all a company has to do is transport unsafe products across state lines for sale and it becomes a federal case. The US Attorney General prosecutes these cases on behalf of either the FDA or FSIS.

Food-related lawsuits are most often civil suits. However, a criminal case may be filed if the action itself was deliberate (intentionally tainting or mislabeling food or knowingly using unsafe ingredients). Felony charges also could be filed if the company knew or suspected there was something wrong with the product and continued to sell it-or attempted to hide the facts from inspectors, customers, or consumers-adding the charges of "willful blindness," intent to defraud, and conspiracy. Criminal liability extends to any employee or company officer who might have been in a position of responsibility, such that they could have prevented the problem. Hefty fines (in the millions of dollars, even for misdemeanors) and imprisonment (for felonies) have been the results of past convictions.

Legal experts say if there is a chance both the company and individual employees will be sued, it is advisable for the employees to retain their own separate legal counsel. This is because there is always a chance that the interests of the individual and the company will conflict as the case progresses. 


\section{Moving Forward}

As unlikely as it may seem when you're in the middle of a recall, there is some good that should come of it. First, it has forced your company to learn how to do some things better and provide an opportunity for the company's continuous improvement program. You might have redoubled your safety or training efforts, improved recordkeeping methods, and become better organized. It was learning the hard way-but it was learning.

Second, you have the opportunity to build a new level of trust and improve relationships with your direct customers. It is time to thank them sincerely for the help they provided during the recall. Let them know your operation is back to normal, and that their continued support is valued. Go beyond the financial costs of the crisis to determine exactly how it has affected them and their customers. You might ask them in survey form, then use the feedback to make positive changes, and be sure to inform them of these changes. Stay in touch with them, and keep your website updated with good information. This is all part of your continuous improvement program.

Third, the recall might have opened up dialogues and relationships with members of the news media that you can build on and benefit from. Reporters naturally notice your company when it's in crisis; now that they know you, it's your job to make sure they know your company's whole story, not just the crisis chapter. Now that you know who they are-and they know something about you-resolve to keep them informed of new plans, organizational changes, feature topics or other newsworthy issues in your industry. Let them know they can contact you as an ongoing resource. Remain accessible and maintain the level of trust that has been established during the crisis.

Fourth, your employees and managers have been put under a great deal of pressure during the recall. There may have been some finger-pointing and infighting about how to handle the various steps, and tempers may have flared as patience ran short. Recognize that your company needs time to heal. Use this period to reward those who made significant contributions to the recall effort. Rewards can be financial, or they can simply be recognition in your internal communications. Ask workers for their input about how things can be done better from now on. You might be surprised at their commitment and creativity. 
And finally, use your experience to help others in your industry. As a recall team, discuss how well your allies rallied around you when you needed those-trade groups, civic organizations, suppliers, shareholders. If you see weak links, this is the time to shore them up. The fact is, no type of food product is immune from problems or the possibility of a recall. Being proactive and well-prepared significantly minimizes your recall risk and improves the chances of carrying out the most effective damage control, should it be necessary. 


\section{Chapter 5: "My Best Advice"}

\section{Advice from the Prosecuting Attorney}

Bill Marler, founding partner in the law firm Marler Clark in Seattle, Washington, is perhaps best known for litigating against the quick service restaurant chain "Jack in the Box, Inc." in 1993 for serving people ground beef contaminated with a deadly strain of $E$. coli bacteria. Since then, his firm has specialized in food-related liability cases on behalf of consumers. Marler testified before Congress for the legislation that became FSMA; today, he has a signed copy of the law on his office wall. He also has launched four websites: Food Safety News, Food Poison Journal, Outbreak Database and Real Raw Milk Facts. Since 2012, Marler has been on a list of "Top 50 Most Powerful People in Food" compiled by The Daily Meal, a popular foodwebsite.

\section{Q: Anyone would agree that the FDA is under-funded and under-staffed. In light of its greater} responsibilities under FSMA, how confident are you in the agency's ability to step up to the task?

A: I'm a big fan of publicly paid inspections - this is one of the things that I believe government should do. But the reality is that the public doesn't have an appetite to fund the FDA to a level that allows that to really work. So, they're being realistic with FSMA. No, there won't be an inspector in every plant, but companies are being required to be proactive, with more extensive HACCP plans and more testing. Much more of the burden of creating safe food is being put upon the industry that's producing it.

Some people say, "That's the fox guarding the henhouse!" In some respects, I don't disagree. But the law reflects the financial reality of government. I believe that with some level of oversight, random though it may be, along with new testing protocols such as whole-genome sequencing and more aggressive criminal investigation and prosecution, I am hopeful that FSMA can do the job.

\section{Q: Do you think the felony convictions and prison terms for the executives of Peanut Corporation of America and some of the massive fines in other high-profile cases have been giant wake-up calls for food companies?}


A: I speak at conferences all over the world, and I'm being asked often to discuss the topic of criminal and civil liability, so it's on their minds. I think it's definitely having an impact. My hope is that the feds keep at it, because it will make people pay a bit more attention.

\section{Q: Do you give companies any different advice than you did, say, in the 1990s?}

A: I spend more time talking about empowering your employees, to help them help you avoid the next big disaster. In each foodborne illness outbreak, in my experience, there always is a chance to turn the bus around before it goes off the bridge. So, I ask companies to really think about whether they have quality, committed people on board. How do you create a food safety culture, where people just sort of organically pay attention to the things they're supposed to pay attention to? And do they have a conduit to raise their concerns to people who are decision-makers? Foodborne illness outbreaks are not usually knowingly committed-it's not paying attention to some test results that don't seem to be a big deal, not paying attention to new data about bacteria, not being engaged enough to pay attention to the things that could harm your brand and your customers.

\section{Q: Just the sheer globalization of food-supply chains can't help but be an issue.}

A: I'm involved right now in some Hepatitis A cases, from scallops in Hawaii and strawberries imported from Egypt to Virginia. I was talking with a doctor friend of mine and asked if he recommends that his patients get Hepatitis A shots. He said, "Only those who travel overseas."

I said, "Well, what about the food that's coming in from overseas?" Some of it is contaminated with Hep A because Hep A is endemic in southern-hemisphere countries. It doesn't harm anyone in Egypt or the Philippines because they've all had Hepatitis A when they were kids-but that isn't the case in the United States.

When you're importing foods into the US, those are the kinds of things you should learn more about and be thinking seriously about. And this also crosses over to issues of homeland security and preventing bioterrorism.

\section{Q: When, if ever, should a company protest a recall request?}


A: Of course, FSMA has given FDA the authority to order a mandatory recall now, so companies have fewer options to actually refuse a recall request. But my view has always been that if you negotiate with the agency for a couple of days, those are two more days that people could be out there consuming your product. That opens the door not just for compensatory damages, but for punitive damages for failing to act to protect the public when you know that your product is potentially tainted. So, the bottom line from my perspective is, the minute-the second-that you think your product is tainted, you should be recalling it and you should have a recall "SWAT team" and plan right off the bat. It should be completely second nature as to how to do it, who to contact, how to get to your customers, what kinds of calls to make. Have the whole thing pre-planned. And be on it quick, primarily because you don't want to sicken any more of your customers, because especially those that you sicken after the recall announcement, it puts you at risk of being hit with punitive damages, which are not covered by insurance.

\section{Q: Speaking of insurance, what kinds would you recommend a company get?}

A: As much as they can! [laughs] I'll give you an example. In the Jack in the Box case back in 1992-93, it had only been about six months before the (E. coli) outbreak happened that there was a new board member who was an insurance executive. He looked at the amount of insurance in light of the amount of risk the company had-considering the number of stores and stuff-and said, "You guys need at least four times the insurance that you currently have." So they increased it from $\$ 25$ million to $\$ 100$ million. In fact, they spent all $\$ 100$ million on liability cases. Without that additional $\$ 75$ million, the case would have bankrupted them. As it was, they literally had enough insurance money to pay and they were proactive with their insurance company, so most of the claims were handled relatively quickly.

That's the power of insurance. The balance is having enough. I can tell you in a lot of cases, especially in small companies, they don't have insurance and wind up being at high risk of going bankrupt.

\section{Q: What do you tell companies to keep, or not keep, in terms of records?}


A: Nobody needs to keep records longer than the statute of limitations, which varies from state to state. My suggestion is to ask your lawyer what the statute of limitation is in your state, and you should have an ongoing document retention policy that does what it's supposed to do. Don't archive or destroy records sporadically-do it on a very consistent basis. Don't start destroying documents the minute you find out you're doing a recall, or you're being sued. That'll just be a disaster for you, because nowadays, there is never one document anywhere. The one you're trying to destroy is always floating around somewhere else, 4 or 5 copies of it that an enterprising fellow like myself will find! So companies need to have a document retention policy that makes logical sense, and follow it. If you destroyed things last Thursday, make sure it's because they were three years old and it was the logical time to destroy them according to your policy. Make a policy and stick with it.

\section{Q: What about emails?}

A: Same thing. There are innumerable examples I've been involved in where I've gotten courts in civil cases to seize hard drives and require the company to pay for somebody to come in and go over those hard drives. I've found many, many, many emails that are exceedingly embarrassing. So people need to have both a hard-document and electronic-document retention policy, and it needs to be consistent. If you have a recall and have four years of files on hand and suddenly decide, "Gee! I think we can destroy three years of this stuff!" That would be a bad idea.

\section{Q: What's your advice on hiring an attorney to be on the recall team from the beginning, to be in the loop and learn the processes and learn about the company?}

A: Well, most companies in my experience don't have an ongoing relationship with an attorney. Y' know, nobody likes attorneys-hell, I don't even like attorneys! The companies that successfully deal with outbreaks and recalls well are those that have ongoing relationships with a lawyer who understands his or her role. That role is to advise the clients how to protect themselves-someone who understands a document retention policy, and ongoing compliance issues in whatever form. But in order to save money, most companies don't bring a lawyer in until something goes wrong. And what happens is, when something goes wrong you call your 
insurance adjuster. The lawyer for the insurance company contacts you and says, "Oh, I'm your lawyer!" Well, then you need to step back and say, "Is that person really my lawyer? Who pays his bill? The insurance company! I wonder if he has my best interest at heart, or the insurance company's?"

I've found that those companies that try to be penny wise and pound foolish by not having an attorney and relying on the insurance company attorneys are the ones I absolutely rip apart and leave their bones.

\section{Q: The last time we spoke, in the early 2000s, you said, "The reality is that there is very little pressure on companies to reform, because there's very little chance they'll get caught." Do you still feel that way?}

A: I think there is more pressure on companies today, because of FSMA and because of consumers' greater interest in and attitudes about safer food. There's also more pressure because testing is much more sophisticated and more readily available. I think about the big Listeria outbreaks - people who might have gotten sick four or five years ago, or might even have died, and testing is virtually giving them the chance to reach out a hand from the grave and be counted as part of an outbreak. So yes, I do think there's added pressure on companies now. And when you overlay that with the criminal liability risks, there's no good reason to not pay attention.

All of this comes down to two things, from my perspective. One, there is really a moral reason to not poison customers. They're usually nice little old ladies or children, and you run the risk of killing them or absolutely ruining their lives. I see it every day, and I make multimillion dollar settlements in cases for kids who run the risk of losing their kidneys, or are brain-damaged, or are now diabetic. There's not one of those kids or their parents who wouldn't rather have their health back than the money. So to the companies, I say, "Hey! It could be your kid, or your grandkid, or your neighbor."

Two, there is a business reason not to do it-and that is, every once in a while, you might get caught. If you want to play the odds, chances are you will get caught. And if you get caught by a lawyer like me, who knows what they're doing, I will do everything in my power to take you to the ground. That's what I do. 


\section{Advice from the Crisis Communications Expert}

A former NBC News correspondent, David Margulies is a nationally known expert on crisis prevention and crisis management, and the author of Save Your Company, Save Your Job: Crisis Management in the Internet Age (CreateSpace, 2010). His Margulies Communications Group has handled communications for about 50 product recalls since 1986. Based in Dallas, Texas, his company provides strategic public-relations (PR) counsel for clients ranging from Fortune 500 companies to nonprofit organizations and government agencies.

\section{Q: At what point are you generally contacted when a problem comes up?}

A: In many cases we've worked on, they were an existing client, so we are already part of the team and would be notified in case of a crisis situation. And a "crisis" is defined as anything that threatens your business or your reputation. We need to know about it as soon as the company sees there's a problem-and before they know it's going to be a recall.

Communicating the government-mandated news release is fairly straightforward; they have guidelines for what they want you to put in it, and you can't deviate from that very much: Here is the problem, how to identify the product, and so on. You want to be careful to also add information such as, "The recall only applies to these products. None of our other products is affected," when applicable.

The issues we deal with are, in many ways, more significant to the client - such as, what does the recall do to your relationships with your customers? And by customers, I don't mean so much the average consumer. The question I ask the company is, "Who could pull the plug on your business?"

\section{Q: When a company first makes the call to you, what are you going to need from them?}

A: The last thing you want to do is call somebody like me if you don't know who they are. Every PR firm says they do crisis communications - so, what you want to do is vet some of them and get to know who's out there working in this area in your industry, and choose someone who knows at least something about your business. In a crisis, you don't want to have to spend a lot of time teaching them about what you do - it's like trying to change a tire when you're already 
driving at 60 miles an hour. So, ask suppliers you trust, people in your industry, for their recommendations. This kind of firm should be part of your crisis communications plan. A good crisis management firm can help you avoid making serious errors that can damage your brand.

We also need the basic facts, right up front - what's the product? What's the problem? What kind of documentation do you have? What have you given to the government agency so far? We need enough to walk them through the media and communications part of it.

Our corporate clients are very sophisticated and really care about safety, because it's important to their business. But there are some people who see it as totally unfair that anyone would want to do a story about their company's product recall-they really get angry about it, and that isn't helpful.

The other thing that I tell people to avoid is denial. The last thing you want is a situation where yes, you knew you have a problem, but avoid dealing with it in a timely manner or "it's not that bad."

You also have to have a culture where people are not afraid to raise a safety issue internally. You need a devil's advocate in the company. People, especially those who are responsible for the problem, are not going to be anxious to call the boss and say, "Hey, we screwed up," in a culture where they're going to get blamed for it.

\section{Q: Give us an example of something a company might not have thought of in advance.}

A: Most companies have a process, and it's pretty well established, for getting product off the shelf in a recall situation. What they might not have nailed down is a thorough understanding of who will want to know about this recall? Be sure to ask that question in advance.

The very first recall we worked on, one issue was who was going to be the company spokesperson. You can't assume it will be the president. In this case, I was told, "No, he doesn't like to do that; and he's going to have other, more important things to do in this process."

In this case, it was clear that the president of this (food processing) company needed to be talking to the supermarket chains-today, if you're doing business with a retailer like Walmart, that might be 10 percent of your business.

So, as a business owner, you want the recall handled correctly, obviously. But from a business perspective, you want to make sure that your buyer-at Walmart or Safeway or any of 
these big supermarket chains-doesn't pick up a newspaper and say, "What the heck is this?" The first thing you want to be doing is talking to your biggest customers.

\section{Q: And if your product is on their shelves, they might also be asked questions about it, by customers or the news media.}

A: You don't want to say, "Take the product back for a full refund," and have a retailer say, "I didn't agree to that," or "I don't want to do that."

Then, as an executive of a corporation, you have a board of directors, you have insurance companies, the health department and any agencies involved in the recall, your legal counsel - there are all kinds of people you need to be dealing with. So, it's OK to select someone else to be a spokesperson. In the Listeria case, the recall team selected the head of human resources for the company, who was very credible, liked dealing with reporters, and was good at it, while the CEO was dealing with these other groups and concerns.

Now, the other issue with this company was, you have your big retailers, then you also have hundreds or even thousands of smaller accounts. And the only people those folks know are the ones who deliver the product. They may not know much about the corporation, or even where it's located. So, we had a very aggressive communications plan with the route drivers: This is what's going on. This is how to answer your customers' questions. And we always give them a toll-free number to call in case there's a question they can't answer, or someone doesn't seem satisfied with their answer.

For the people answering the phones, you want to write a Q-and-A for your customerservice representatives or for dealing with the public or the news media. If there is a predictable question, you already want to have an answer.

\section{Q: Is it the norm for a company to ask that no employee speaks to a member of the news media during a recall, and to make that part of the crisis communications plan?}

A: That's the norm, and the reasons are that you want the message to be consistent and accurate, and that it doesn't cause you some other, unanticipated problem. We've had a lot of cases where the attorneys have looked at what we wanted to say and said, "If you say that, it 
jeopardizes our insurance coverage." There are all kinds of legal minefields and nuances that may not be readily apparent to someone without experience in crisis management.

Also, you want to make sure that the person who does talk to the press knows who they're talking to. I mean, Mike Wallace and Charles Kuralt both worked for CBS, right? But one was an investigative reporter, the other did feature stories. So, who's calling is really important, and you can't have six people making six different statements.

\section{Q: Has social media complicated this process?}

A: Not necessarily, but it speeds it up. And it means that you not only have to be fast, but you have to be very accurate-because if you write something that's inaccurate, a million people out there will correct you. It's like you can only do so much to control the flow of information anymore.

If you said, for example, "We've never had this happen before," you can bet someone will come back and say, "Oh, I remember back in 1954..." So, focus on being very factual, and also resist the temptation to overreact. There are some pretty outrageous things that get circulated on social media, and we evaluate whether any of them is gaining steam. You don't want to build a fire under the thing by responding and going back-and-forth if it's an allegation that is just nuts! You have to let it go.

The other thing that's very important is bringing closure. If you look at some of these cases, such as the Blue Bell ice cream case-we didn't work on that one, but it seemed to go on forever-every couple of days there'd be more news, worse news, more cases, more plants involved.

With our Listeria case, people would call the next day and ask, "What's new?" And we could say, "Nothing. Same things that were going on yesterday. We're just doing what we said we would do." So as a result, the news coverage pretty much died down. We didn't offer any new ideas for reporters to jump on, about how all the recalled product would be disposed of or any other topic.

\section{Q: Tell us a little more about this particular recall.}


A: It was a dairy, and Listeria was found in the plant-as far as we know, it never got into the product. But they made the decision to recall all of their production and remediate the problem in the dairy. It didn't take long to fix it, but they had the issue of getting all this milk back, in huge amounts-it's heavy; it's bulky; there's a lot of it-and replacing it with fresh product.

The whole process took three or four days - not long, because in this case, they were able to isolate the problem quickly. You want to move quickly because if it's a serious problem, people could get sick or even die. For the same reason, you need to document whatever you do, so that if you have regulators or litigators asking about it, you have a careful record of it.

For example, one of the most frequent requirements is that you send out a news release. We use a news wire service, and we document it - we get a receipt from the news wire confirming that it went out. And if the recall involves two states, we don't send it to the whole country.

The big thing for consumers is, generally, the news coverage on this recall was big because it's a local company, well-known, and it affected schools and everybody. But most news releases don't get picked up by many news outlets. Unless you have major illnesses or a problem that has gotten out of hand, in most cases a recall doesn't get a lot of press.

I would say most of the issues we've been asked to help deal with involve mislabeling, and that can happen very easily-you put the wrong lid on an ice-cream container. There are so many recalls, and so many are small, that there isn't a lot of news coverage.

\section{Q: Where does internal communication fall in making recall plans?}

A: In the Listeria recall, we knew that the people who were dealing with our customers, that's who the customer knows. They know the person who pulls up in the truck and delivers the milk, and those people were working overtime to get this solved. So, we kept in touch with them and told them what was going on. "Focus on your customer, focus on your job. This is how we're handling the situation and we'll continue to keep you informed." As long as they see that things are continuing to operate smoothly, then they're usually fine with it and very supportive. But it's important to keep them in the loop and keep the discussion focused. If you have questions, ask your supervisor. And we always like to have a toll-free number so if anyone has a question or problem, they can give it to the customers so they can call. 


\section{Q: Exactly who decides whether or when to do a recall? In terms of public relations, does it look better to initiate your own recall instead of waiting for an agency to say, 'We recommend a recall?'}

A: There are some cases where you may disagree with the regulatory agency on whether a recall is necessary; it's not quite as cut-and-dried as it sometimes appears. So, the answer is, most of them are routine. But if it's very controversial, then saying you'll voluntarily recall is nice, but it's not going to get you much. We definitely put it in the news release: "The company has voluntarily recalled all affected products..."

Whatever the government agency decides, that's what we do. We try to be really careful, and I think this is an important thing to think about-you never want to be in a position in a controversy or a lawsuit, where you say, "Well, I asked the public relations firm what they thought we should do." If we did, that just looks horrible for you. The perception would be that you're more concerned about your image than about your customers or consumers.

Our position is, as a company, you have food safety experts and legal counsel. You guys decide what to do and we'll execute based on that.

\section{Q: What if the company truly disagrees with the regulatory agency about the need for a recall?}

A: You don't argue with regulators in public-because if you stay in business, you will be working with these agencies long-term. You may have an honest disagreement, and if you feel strongly that you want to assert a different position, you hire someone who is an expert in that area of the law and you work with them and the agency privately to address those issues. Publicly, you are always working together to protect the public. There is no percentage in getting into a fight with someone who regulates your business.

I have had regulators be very helpful and respectful. They have a job to do, they have a process to follow, and overall I've found them to be very reasonable. They want safe food-so do my clients.

\section{Q: Any final advice for food processors and distributors?}


A: Every organization needs to ask itself, "What kinds of problems occur in our industry and how are we going to be sure that we have the structure to deal with them?"

The analogy I always use is the airline industry-if there's a problem in the cockpit, they have a book that lists all of the different things that can go wrong. You tab to each thing and it says, "Do this, this, this, and this." You want the same thing in your company. If you're in the food business, there is a chance you're going to have a recall-it's a predictable event. So, there's no good reason not to sit down and decide: Who will be in charge of dealing with the government agencies? The customers? The suppliers? Have your crisis plan mapped out so that it's as close to a routine as you can make it.

I think one of the worst cases I ever dealt with was a company that was visited by government inspectors for a potential food poisoning problem. One of the employees emailed another and said, "Don't worry-the feds were here, but I lied to them."

So, you want to educate your employees as well-what are their responsibilities in dealing with the agencies, with inspectors? And these lessons can be imparted in a positive way: "This is how you do it, this is who you call." You might be surprised to learn that some of your middle managers don't realize you have corporate counsel.

And finally, remember that a crisis never happens at 9 a.m.-it's always on Friday afternoon or a holiday, or when somebody's on vacation. That's why you also have to have a backup for each person on the crisis team. 


\section{Advice from the Recall Team Member}

Mike Resch is the Executive Vice President of Administration and General Counsel for Amy's

Kitchen, Inc. Headquartered in Petaluma, Calif., Amy's Kitchen is a family-owned, privately held company that for nearly 30 years has manufactured and marketed vegetarian convenience foods made with organic and non-GMO ingredients.

\section{Q: Tell us about your recall team and who's on it.}

A: Amy's recall team includes all the functionary areas necessary to help gather and evaluate the relevant facts and, if need be, to implement a recall. This includes representatives from our office of general counsel, quality systems and supplier quality groups, regulatory affairs, sales, manufacturing group, consumer relations, marketing, sourcing, logistics, planning, human resources and finance.

\section{Q: Are there other outside professionals that you've already vetted that you can call in if needed?}

A: We have a public relations firm and a crisis-management firm that we consult with as needed. We also have relationships with outside experts, including law firms, microbiologists, and testing labs. We've got years of experience with particular labs that have wonderful reputations in the professional community. We work with these labs regularly, and, in case of a recall, we'd identify the best fit depending on the situation.

\section{Q: Does the team meet regularly, or only as needed?}

A: We have certain members of the team who meet regularly and discuss our state of preparedness, internal compliance, audit results, training, and other issues. Within our recall plan we have a contact flow or contact tree that reflects the order in which folks are to be notified.

\section{Q: Do you have sample documents prepared in case you need them?}
A: Yes. 


\section{Q: How would you say FSMA has affected your whole food safety effort, in general?}

A: FSMA has dramatically enhanced the FDA's regulatory authority and, in the process, has more clearly defined the nature of the practices and precautions that the food industry is expected to implement and observe. We welcome these developments, as well as the nowclear paradigm that food safety is a shared enterprise between industry and the FDA.

Our response to FSMA has been thorough and has meant an enormous dedication of resources and priorities. Some of the specific areas of investment are, for example, enhanced internal auditing, improved documentation processes, more intense and frequent training and retraining, revising and creating new Standard Operating Practices (SOPs), and revising our food safety plans and supply-chain programs. We've instituted programs and trainings to raise food safety awareness across the entire organization, in each department. We're also preparing for Safe Quality Food (SQF) certification.

\section{Q: A recall can't help but affect your relationships with suppliers--especially when it's a} supplier's problem that caused you to have to recall product. How do you handle that situation, having to rethink and perhaps even decide whether to keep that relationship?

A: Our first and paramount interest is the safety of our products. From the start of any supplier relationship, this expectation is made clear and we try, through our supply chain program and efforts like our annual Supplier Summit, to reinforce this expectation.

To this end, we regard our suppliers as partners and believe in developing collaborative relationships. We have been proactive in working with them in best practices, from a food safety and quality perspective. In our Supplier Summit, we talk about a lot of these issues and try to share the learning that our technical experts have gained, to improve the overall foodsafety culture of the suppliers. We have breakout sessions and presenters on various topics so they can learn from us, and we can learn from them.

Once an event occurs and we're notified that a supplier is going to have a recall, our focus is on our consumers. The best way to make sure we see the implications for Amy's and our consumers is to work cooperatively with the suppliers to understand the impact, the scope, and what the supplier is learning from its own experts, internal and external. 
In this process, we hope there isn't tension created based on the impact of the recall, but of course there will be insurance companies that get involved. You try to navigate that communication process as professionally and courteously as you can.

At the same time, we do a thorough analysis of the impact of a recall event, and part of that is assessing whether our approval of that supplier should be questioned, what corrective measures the supplier should implement, and whether we should take action to suspend or disqualify a supplier.

\section{Q: Amy's Kitchen uses so much fresh produce. With FSMA and farms, there probably are many questions about how it affects farmers, different types and sizes of farms.}

A: Under FSMA, certain farms are subject to new standards for safe growing, harvesting, packaging and holding produce. Part of what we see is an opportunity to help educate suppliers, especially those who aren't as big or sophisticated as others, or who don't have the resources to hire lawyers and other outside experts-notably microbiologists well-versed in preventive controls - to advise them. We try to be a resource, too.

\section{Q: You mentioned getting prepared for SQF certification. Why is that important?}

A: We go through rigorous internal and outside audits, but getting to an SQF certification is part of our way of ensuring that what we're seeing internally fits within what an outside, independent certifying body would see as well. It's a further check on safety and quality. In terms of FSMA compliance, it's not a complete overlap because every organization is looking at different things, but it's a large overlap with many of the FSMA principles.

\section{Q: What's the biggest challenge in preparing for a recall, in your view?}

A: For Amy's Kitchen in particular, we've got a very complex manufacturing program that involves many different control points because we produce numerous products for people with food sensitivities. We've also got hundreds of SKUs. So for us, I think traceability is a critical focus. We may have one ingredient flowing through to many different finished goods, so assessing the scope and extent of possible exposure to a potential contaminant is an urgent and demanding task. In light of time constraints, it often has to be done based on less than a full 
plate of information. As a result, our risk estimates can understandably be more conservative in terms of protecting public health than what actually might be the case.

I should add that just notifying all the different people and entities who have to be notified in a recall action can be a challenge. But it's a challenge made more doable if a robust traceability system is in place.

\section{Q: Any thoughts on recall insurance?}

A: Each organization needs to give very serious and careful thought to what kinds of insurance to get, as well as the limits of the insurance. I think many times your hope is that those costs and the impact will be covered by the supplier's insurance, to the extent that it's a supplierdriven recall. But time and time again, suppliers' insurance carriers are slow in processing claims, or try to raise barriers about their liability for those claims or coverage of those claims. So, I think having your own recall insurance is an important risk-mitigation step, in the event that a supplier doesn't have the insurance that it needs, particularly for very large recalls that involve a lot of customers.

\section{Q: What's it like to work with the FDA? Is it scary to have them show up at a plant?}

A: My view is that the FDA is there to work from the regulatory and public health perspective, and our role is to assist the agency in that effort. We respect the FDA and its mission and authority, and respect is what guides our dealings with the inspectors and other FDA personnel. As a policy, we cooperate with the FDA. We recognize that we can learn from the agency's perspective and expertise and, in turn, the agency can learn from us.

As for whether it's scary to have agency inspectors show up, "scary"-for me, at leastisn't the right word. For me, their presence is a test-a test that we work hard to help ensure that we are prepared for. So, I think preparing for FDA inspections and understanding the agency's increased authority under FSMA is probably a whole separate topic.

\section{Q: What are your thoughts about communicating a recall action?}

A: I'm a firm believer in transparency in dealing with consumers and coordinating with the FDA. I think it's not only the right thing to do, but it's important for the company's reputation. One of 
the difficult things companies face in a recall event is, things happen so fast that they might not have all the information they need, at the same time they're navigating what information to provide. That's something folks struggle with. In my view, erring always on the side of transparency is key.

From an IT and customer relations perspective, it is also critical to understand what your system can handle. Depending on the expected volume of calls and emails from consumers, be prepared to have an outside call center step in if necessary. You don't want consumers with questions unable to get through, unable to leave messages, or no one getting back to them. If there's even a possibility that your system isn't sufficient to handle the increase, be ready to bring in that outside call center right away.

\section{Q: Anything else you'd like to add?}

A: I feel very fortunate to be at a company where everyone, from the owners to our head of manufacturing all the way down, is 100-percent supportive of the resources needed to respond to the new environment. I would implore all the other food and beverage organizations to devote those resources and understand the need for it and to take a very collaborative approach - not only in responding to the FSMA regulations or an individual recall event but in working to be leaders in food safety.

A recall event can hit in ways that are totally beyond your direct control, and it takes a complete team effort to be proactive in terms of food-safety leadership, every day. You can't just leave it up to one group in the company. Our message is that food safety is everyone's priority, every day, for every consumer. 


\section{Glossary of Key Terms}

Commonly used terms within the text found below are defined for convenience. In addition to these, the US Food and Drug Administration has an extensive glossary as part of its own Regulatory Procedures Manual. This list can be found at:

\section{http://www.fda.gov/ICECI/ComplianceManuals/RegulatoryProceduresManual/ucm179275.htm}

\section{A}

Administrative detention: The Food and Drug Administration's term for ordering a food product to be held in a specific location pending further investigation if an FDA officer or qualified employee has reason to believe the food is adulterated or misbranded.

(Administrative detention applies only to foods under the FD\&C Act, not the federal Meat, Poultry Products or Egg Products Inspection Acts.)

Adulteration: In general, this term refers to contamination of a product that makes it unfit for human use and/or not up to expected product standards. Broadly defined in federal regulations and laws as "filthy," "putrid," "unsound," "unhealthful," or "unwholesome." Further defined by some courts as including manufacturing conditions sufficiently unsanitary that contamination is likely.

Agency-requested recalls: The Food and Drug Administration (FDA) can request a product recall as part of its regulatory sanctions. Agency-requested recalls are most often done when the FDA determines that an already-distributed product may endanger public health or safety or involves a gross consumer deception; that the producing company hasn't initiated a recall; and that the FDA must act to protect the public from exposure to the product. For more details, see www.fda.gov.

Allergen: A food, or substance in a food, that causes an allergic reaction in some people. The substance that makes a food an "allergen" is a protein contained within the food. Food products made without these proteins (peanut oil or soy oil, for instance) do not cause allergic reactions, even though they are made from products typically thought to be allergens. (See also 
the definition of "Big-8.") For more information about allergens: www.foodallergy.org (website of Food Allergy Research and Education, FARE); www.ift.org (website of the Institute of Food Technologists); and www.aafa.org (website of the Asthma \& Allergy Foundation of America). Some preservatives, like sulfites, also are considered allergens.

Allergic reaction: An exaggerated immune system response to a food, drug or other allergen that the body mistakenly believes is harmful. Symptoms vary widely among individuals, but may include: tingling sensation or swelling of tongue and throat, breaking out in a rash or hives, breathing difficulty, drop in blood pressure, nausea, stomach cramps, and diarrhea. In severe cases (see "anaphylaxis"), loss of consciousness or death can result. According to the group Food Allergy Research and Education (FARE), 15 million Americans have food allergies, prompting more than 200,000 hospital emergency-room visits annually.

Anaphylaxis: Hypersensitivity to an allergen that causes a life-threatening allergic reaction. A severely allergic person may experience anaphylactic shock and even death.

Animal and Plant Health Inspection Service (APHIS): This Department of Agriculture (USDA) agency focuses on preventing insect infestations and diseases that affect plants and animals. For details, go to www.aphis.usda.gov.

\section{Audit check: See Effectiveness check.}

B

Batch: A specific quantity of food that is intended to have uniform character and quality, within specified limits, and that is produced according to a single processing order during the same cycle of manufacture.

"Big-8:" The common industry nickname for the eight most common food allergens that are responsible for $90 \%$ of all allergic reactions. They include: eggs, fish, shellfish, milk, peanuts, tree nuts (walnuts, cashews, etc.), soy, and wheat. 
Bioterrorism: A deliberate act that is motivated by a political agenda, and that intends to cause harm to humans, animals, or agriculture. The Centers for Disease Control and Prevention (CDC) has a large database related to bioterrorism, including pathogens and other agents that could be deliberately introduced into food, water, and other consumable products, resulting in recalls.

Botulism: A severe form of food poisoning caused by the neurotoxin botulin. Botulin is produced by a spore-forming bacterium called Clostridium botulinum, widely found in soil and domestic animal intestinal tracts. Human cases generally arise from bacterial development in raw or improperly canned or preserved foods, especially in meats and non-acid vegetables. Botulism can cause cardiac arrest and respiratory paralysis.

C

Causation: A legal term for the act or process of causing something to happen. In the case of recall-based litigation, plaintiffs must not only establish that a manufacturer's product was defective, but that it actually caused an injury. The causation test varies between states. Some states require proof of "proximate causation"-that the injury was foreseeable to the manufacturer; others require only that the recalled product was a "substantial factor" in causing the plaintiff-suffered harm.

Centers for Disease Control and Prevention (CDC): This federal agency provides a system of health surveillance to monitor and prevent disease outbreaks (including those caused by bioterrorism), implement disease-prevention strategies, and maintain national health statistics. Conducts both active and passive foodborne surveillance. It also guards against international disease transmission, with personnel stationed in more than 25 foreign countries. For information, go to www.cdc.gov.

Center for Food Safety and Applied Nutrition, FDA (CFSAN): This is one of six product-oriented centers, in addition to a nationwide field force, that carry out the mission of the FDA. CFSAN, in conjunction with FDA field staff, is responsible for ensuring the nation's food supply is safe, sanitary, wholesome, and honestly labeled, and that cosmetic products are safe and properly 
labeled. For more details, the center's website is at:

http://www.fda.gov/AboutFDA/CentersOffices/OfficeofFoods/CFSAN/.

Chemical contamination: Contamination of food products by pesticides, sanitizing or other chemicals, or by the addition of legal additives at higher-than-acceptable levels.

Class I: a reasonable probability that the use of the violative product will cause serious adverse health consequences or death.

Class II: the use of a violative product may cause temporary or medically-reversible adverse health consequences, or the probability of serious adverse health consequences is remote.

Class III: the use is unlikely to cause adverse health consequences.

Class-action litigation: A legal action brought by one or more persons on behalf of themselves or a much larger group, all of whom have the same reasons for taking the legal action.

Code of Federal Regulations (CFR): The CFR is the body of laws, rules, and regulations upon which US federal government control and oversight are based. The federal regulations relevant to food-based product recalls are contained in CFR 7, Title 21, Parts 1-1271. CFR citations can be obtained at www.gpo.gov.

Commercial General Liability (CGL): An insurance policy issued to a business to protect against liability claims for bodily injury (BI) and property damage (PD).

Consignee: FDA term for anyone who received, purchased, or used the shipped product.

Contamination: The process, either willful or accidental, of causing a product or substance (in this case, a food product) to become impure, polluted, or infected by coming into contact with a contaminant. A contaminant may be biological (bacteria, viruses, parasites), chemical (pesticides, cleaning products), or physical (hair, bits of glass or metal, etc.). 
Correction: An alternative to a recall, this means the repair, modification, adjustment, relabeling, destruction, or inspection of a product without its physical removal from the marketplace. (Inspection can include monitoring affected patients for worsening symptoms.)

Critical Control Point (CCP): A point, step or procedure at which controls can be applied and a food safety hazard can be prevented, eliminated or reduced to acceptable (critical) levels

Critical Limit: A maximum and/or minimum value to which a biological, chemical or physical parameter must be controlled at a critical control point (CCP) to prevent, eliminate or reduce to an acceptable level of occurrence of a food safety hazard.

Customs and Border Protection (CBP): The largest federal law enforcement agency of the Department of Homeland Security (DHS), charged with regulating and facilitating international trade, collecting import duties, and enforcing U.S. regulations, including trade, customs, and immigration.

Department of Homeland Security (DHS): A cabinet department of the US government with responsibilities in public security. Its mission involves anti-terrorism, border security, immigration and customs, cyber security, and disaster prevention and management.

Depth of recall: The level of distribution that will have to be contacted to recall a product. The wholesale level means companies between the manufacturer and the retailer that may have some of the product. The retail level means wholesalers and the retail outlets to whom they sell. The consumer or user level means people who have already purchased the product for home use must also allow it to be turned in, picked up, or destroyed.

Division of Emergency and Investigational Operations (DEIO): The branch of the Food and Drug Administration that investigates criminal food-related cases such as tampering, terrorism, extortion and malicious false reports. 


\section{Division of Foodborne, Waterborne, and Environmental Diseases (DFWED): See National}

Center for Emerging and Zoonotic Infectious Diseases (NCEZID). This part of the CDC is responsible for controlling infectious diseases and tracking emerging problems.

E

\section{E. coli: See Escherichia coli.}

Effectiveness check: This update is performed to verify that all consignees specified in the recall plan have received notification about the recall and have taken appropriate action.

Effectiveness checks may be accomplished in person or by phone, fax, e-mail, and/or regular mail. The recalling company is usually responsible for conducting effectiveness checks, but the Food and Drug Administration (FDA) or a local health department can assist when necessary and appropriate. The FDA publishes a guide, "Methods for Conducting Recall Effectiveness Checks," available upon request from the Dockets Management Branch (HFA-305), Food and Drug Administration, Room 1-23, 12420 Parklawn Drive, Rockville, MD 20857.

Egg Products Inspection Act (EPIA): One of the federal laws used by FSIS to inspect egg processing plants for safety, sanitation, labeling, and packaging. Find the full text of the law on the FSIS website, www.fsis.usda.gov.

Emerging Infections Program (EIP): A program of the Centers for Disease Control and Prevention (CDC). The EIP's Foodborne Diseases Active Surveillance Network (Food Net) actively monitors bacteria and parasites that have recently emerged as human pathogens.

Environmental Protection Agency (EPA): this agency regulates pesticide use and is responsible for establishing safe standards for pesticide residues in raw agricultural commodities and in foods sold in interstate commerce. (The FDA and USDA agencies monitor food products for pesticide residues and enforce EPA regulations.) 
Environmental Laboratory Response Network (ELRN): The EPA established the ERLN as a national network of laboratories that can be called on as needed to support large scale environmental responses.

Epidemiologist: A person who studies epidemic diseases and their control. Along with clinicians, epidemiologists can help companies communicate with government agencies and better analyze the details of foodborne illnesses and how the company can best respond. They can assist in outbreak investigations and in corroborating the regulatory agency's methodology and results.

Epidemiology: The science of infectious diseases and the study of their causes, incidence, distribution, and control.

Escherichia coli (E. coli): A type of bacterium that lives in the intestines of healthy humans and animals, including cattle. Most strains are harmless but one, E. coli 0157:H7, produces a powerful toxin that can cause severe illness. Infection can occur through contaminated meat or milk products that have not been cooked or pasteurized sufficiently. The infection is diagnosed by testing a stool sample; symptoms of E. coli $0157: \mathrm{H} 7$ infection are diarrhea and abdominal cramps. In toddlers and the elderly, it can also cause a complication called hemolytic uremic syndrome, in which red blood cells are destroyed and kidneys fail. In 2014, the CDC estimated E. coli $0157: \mathrm{H} 7$ caused 265,000 foodborne illness cases.

$\mathbf{F}$

Federal Anti-Tampering Act (FATA): The US law that makes it a federal crime to temper with consumer products and authorizes the Food and Drug Administration to investigate these allegations. They include tampering with or tainting a product, knowingly communicating false information about tampering or tainting incidents, or threatening or conspiring to tamper with a consumer product. Read the full text of the law online at:

http://www.fda.gov/regulatoryinformation/legislation/ucm148785.htm. 
Federal Bureau of Investigation (FBI): Is the domestic intelligence and security service of the United States, and its principal federal law enforcement agency. Operating under the jurisdiction of the U.S. Department of Justice and reports to both the Attorney General and the Director of National Intelligence.

Federal Food, Drug and Cosmetic Act (FD\&C Act): The federal law that the FDA and its associated agencies use to oversee the manufacture and sale of food, drugs, and cosmetics in the United States. It defines food as "articles used for food or drink for man or other animals, and chewing gum." (21 USC 301), and drug as "articles recognized in the official United States Pharmacopoeia, official Homeopathic Pharmacopoeia of the United States, or official National Formulary that are intended for use in the diagnosis, cure, mitigation, treatment, or prevention of disease in man or other animals; and/or affect the structure of any function of the body of man or other animals." Read it online at:

http://www.fda.gov/regulatoryinformation/legislation/federalfooddrugandcosmeticactfdcact/

Federal Meat Inspection Act (FMIA): The federal law that authorizes FSIS to regulate the slaughtering of animals and the processing and distribution of meat and meat products. Includes animal food derived wholly or in part from partial or whole carcasses of cattle, sheep, swine, and goats, as well as horses, mules, or other equines. Read the full text of the law online at: http://www.fda.gov/regulatoryinformation/legislation/ucm148693.htm.

Firm-initiated recall: A recall prompted by the company making or distributing a product without notification or suggestion by the FDA or FSIS. Even in the case of firm-initiated recalls, the FDA asks that the relevant district office be notified immediately. The FDA deems these company-initiated removals or corrections "recalls" only if the product may represent a violation subject to legal action.

Food and Agriculture Sector Coordinating Council (FASCC): The FASCC was created by the industry to serve the sector's counter-terrorism and security interests. 
Food Allergen Labeling and Consumer Protection Act (FALCPA): A 2004 federal law (an amendment to the Federal Food, Drug, and Cosmetic Act) that requires food labels to include the presence of any ingredient that is, or contains protein from, a "major food allergen." (See Big-8.)

Food Allergy Research and Education (FARE): This group was established in 2012 by combining the Food Allergy and Anaphylaxis Network (FAAN) and the Food Allergy Initiative (FAI). Its purpose is to raise funds for research and increase public awareness about food allergy and anaphylaxis issues. For details: www.foodallergy.org.

Food and Drug Administration (FDA): FDA is a scientific regulatory agency responsible for the safety of the nation's foods, cosmetics, drugs, biologics, medical devices, and radiological products (both those domestically produced and those imported). It is internationally recognized as the world's leading food and drug regulatory and consumer protection agency. The FDA is part of the US government within the Department of Health and Human Services (DHHS) and the Public Health Service (PHS). Many of the agencies dealing with product recall are FDA sub-agencies. For detailed information on the FDA, go to www.fda.gov.

Food Emergency Response Network (FERN): Provides for an early means of detecting threat agents in the American food supply. FERN integrates the nation's food-testing laboratories at the local, state, and federal levels into a network that is able to respond to emergencies involving biological, chemical, or radiological contamination of food.

Food and Nutrition Service (FNS): The USDA agency responsible for administering many of the federal food-related programs for low-income families, including School Breakfast and School Lunch Programs; the Child and Adult Care, Food Stamps and Food Distribution Programs, and the Women, Infants and Children Program. These programs use USDA commodity foods.

Food Safety and Inspection Service (FSIS): This Department of Agriculture (USDA) agency inspects more than 6,000 processing plants to ensure the proper processing, safe handling, and correct labeling of meat, poultry, and egg products. This includes humane slaughtering of 
livestock, sanitation, safe transportation and storage, and proper disposal of condemned product. FSIS oversees approximately 25 percent of all food in the United States, using many of the same guidelines and methods, and possessing the same type of legal clout, as the FDA. For more information, go to www.fsis.usda.gov.

Food Safety Modernization Act (FSMA): A federal law signed in 2011 that outlines requirements for a greater food-industry focus on preventing foodborne illness and that expands the FDA's responsibility for enforcing food-safety laws, including giving the agency the authority to demand a product recall action. FSMA's sweeping requirements can be roughly divided into these key areas:

- Preventive controls. Requires that companies across the food-supply chain have comprehensive, prevention-based controls and plans in place to minimize foodsafety hazards, both for human food and animal food. Requires that evidence of these controls and compliance records be made available to the FDA uponrequest.

- Bioterrorism prevention. Requires that all facilities' food-safety plans in the United States and abroad address vulnerabilities to prevent adulteration of the food supply "with the intent to cause large-scale public harm."

- Inspection and compliance. Requires the FDA to improve its inspection programs and be proactive, focusing on prospective risks in addition to addressing existing threats.

- Produce safety. Establishes science-based standards for preventing foodborne illness for companies that grow, harvest, pack, and hold produce, both domestically and in foreign countries.

- Imported food safety. Requires importers to verify that their foreign suppliers have adequate preventive controls in place for food safety. Establishesa Foreign Supplier Verification Program (FSVP) and gives the FDA authority to accredit third-party auditors to inspect foreign facilities to ensure compliance with US food-safety standards.

- Expanded enforcement. Gives FDA mandatory recall authority for all food products. 
Expands FDA's authority for administrative detention of potentially hazardous food products, and its ability suspend a food facility's registration.

- Enhanced partnerships. Directs the FDA to improve food-safety training at all levels of government, and to strengthen partnerships within the United States and abroad to increase and improve collaboration on food safety. This includes creating a certification program to accredit third-party food-safety auditors, in the United States and in foreign countries.

- Sanitary transportation. Requires companies that transport food to use sanitary practices to ensure food safety.

The FDA's FSMA website is: http://www.fda.gov/Food/GuidanceRegulation/FSMA/

Food Safety Preventive Controls Alliance (FSPCA): A public private alliance consisting of industry, academic and government stakeholders who developed a nationwide core curriculum, training and outreach program to assist companies in complying with the preventive controls regulations that will be part of the Food Safety Modernization Act (FSMA).

Foodborne Diseases Active Surveillance Network (FoodNet): This network is the primary foodborne disease element of the Emerging Infections Program (EIP) in the Centers for Disease Control and Prevention (CDC). FoodNet monitors which foods cause the most foodborne illnesses and actively surveys laboratories for diarrhea illness cases-the most common symptom of foodborne illness. FoodNet also conducts random population surveys on diarrhea illness and conducts epidemiological studies on targeted pathogens. For more details, go to www.cdc.gov/foodnet

Foreign Supplier Verification Program (FSVP): See fifth bullet-point in definition of Food Safety Modernization Act (FSMA).

G

Good Manufacturing Practices (GMPs) also referred to as Current Good Manufacturing Practices (CGMPs): Are regulations enforced by the US Food and Drug Administration (FDA) 
that provide for systems that assure proper design, monitoring, and control of manufacturing processes and facilities. Title 21-Food and Drugs, Chapter I-FDA Department Of Health And Human Services (HHS), Subchapter B-Food for Human Consumption, part 117 Current Good Manufacturing Practice, Hazard Analysis, and Risk-Based Preventive Controls for Human Food. (https://www.accessdata.fda.gov/scripts/cdrh/cfdocs/cfcfr/CFRSearch.cfm?CFRPart=117\&show $\underline{\mathrm{FR}=1)}$

H

Hazard Analysis and Critical Control Point (HACCP): A food safety system developed for NASA (US Space Program) that includes seven (7) steps for identifying potential hazards; critical control points (proper temperatures for storage, cooking, thawing, etc.); monitoring and correcting problems; and establishing an effective record-keep system to document that the system is working. Federally inspected meat and poultry plants and all producers of fishery products and juices are required by federal law to develop and implement HACCP plans.

Hold: A time period used for investigation after a USDA commodity food has been identified as potentially unsafe. The agency has a maximum of 10 days after receiving a complaint or identifying a product to make its recall decision. During this time, recipients of the food are instructed to isolate it and not use it, effectively "holding" it until its safety has been determined. The hold process is unique to USDA commodity foods.

Homeland Security Presidential Directive (HSPD): Executive branch documents laying out the national strategy to secure the homeland. (https://www.dhs.gov/presidential-directives)

Infant formula: Until passage of FSMA, this was the only product for which the Food and Drug Administration could demand, not just request, a recall. Infant formula is governed by 21 CFR, 107; infant formula recalls, Subpart E.

Injunction: A court order that prohibits a person, group, or company from carrying out an action. When a company refuses to voluntarily recall a potentially dangerous or defective 
product, an injunction can be sought by the Food and Drug Administration (FDA) or state courts and/or regulatory agencies to stop its continued distribution or sales.

Investigations Operations Manual, FDA (IOM): The IOM is the primary guidance document on FDA inspection policy and procedures for field investigators and inspectors. The IOM is sometimes supplemented by but not superseded by other manuals and field-guidance documents. Significant departures from IOM-established procedures must have the concurrence of FDA district management. The FDA welcomes suggestions for changes and updates to the IOM. Suggestions can be sent to the Division Of Field Investigations (HFC-130), 5600 Fishers Lane, Rockville, MD 20857 or via e-mail to Director, DFI. You can also send email regarding the IOM at IOM@ora.fda.gov. For a look at the IOM:

http://www.fda.gov/ICECI/Inspections/IOM/default.htm

L

Labeling: The written or printed information on a product that contains ingredient and nutrition information. Three critical areas to consider in food labeling are:

- whether it is easy for consumers to understand ("milk derivative" instead of sodium caseinate, "cashews" instead of tree nuts, etc.);

- whether the advisory statements included on the label are understandable and actually helpful to consumers. Manufacturers often useblanket statements ("May contain...") which gives little useful information and limits the choices for foodallergic consumers; and

- whether low-level ingredients are adequately labeled instead of being lumped into descriptions like, "flavorings, spices, or colors." There is currently no standard rule about identifying potential allergens that are present in very smallamounts.

The FDA has extensive product-labeling guidelines for industry. These are online at: http://www.fda.gov/Food/GuidanceRegulation/GuidanceDocumentsRegulatorylnformation/La belingNutrition/ucm064880.htm 
Laboratory Response Network (LRN): Was established by the Department of Health and Human Services (HHS), Centers for Disease Control and Prevention (CDC) in accordance with Presidential Decision Directive 39, which outlined national anti-terrorism policies and assigned specific missions to federal departments and agencies.

(https://emergency.cdc.gov/Irn/index.asp)

Legal counsel: Attorney(s) hired to represent a company regularly. Pre-established arrangements with recall-knowledgeable attorneys are key to any recall strategy. When a foodborne illness outbreak may spark a product recall, having an attorney already familiar with the company means quicker and more effective legal counsel to help company officers look at options and make decisions. Attorneys can also be valuable as investigators and interviewers because of their legal training. For more information about legal food-related issues, including a list of referrals, see the Food and Drug Law Institute website, at www.fdli.org. Depending on the circumstances of a product recall, individual company officers and other associated parties may need to retain legal counsel independent of the recalling company. Part of any company's recall strategy should be a process by which the company assesses the way employee and company interests may conflict in the event of a recall and whether a company should provide and/or pay for separate counsel for employees.

Letter of Warning (LOW): An enforcement device used by FDA and FSIS as notice for minor violations of law. A LOW may be issued to any individual or business, from a restaurant or retail store to a wholesaler, distributor, or processor of meat or poultry products. The letters warn that the agency "may seek criminal action based on continued violations," and indeed, receipt of a series of LOWs may prompt referral of the case to a US attorney for prosecution.

Liability: Liability definitions vary widely between states, so check with your attorney about the states in which you do business. However, here are a few common terms:

- Civil liability usually means harm was done without intent.

- Corporate officer liability means company officers can be found criminally liablefor violations if they held a "responsible position" from which they could have 
prevented the violation. These officers include but are not limited to presidents, general managers, and quality-control personnel.

- Criminal liability indicates the law was deliberately broken or ignored.

- Strict liability means a company can be held liable for simply producing a defective product, even if the defects were not a result of negligence or other aggravating factors. Among states, liability thresholds vary from "consumer expectation" to "riskutility" to "it is in a condition not contemplated by reasonable persons."

- Strict misdemeanor liability may be the legal charge if a prosecutor proves onlythat a product was defective, not that the manufacturer or distributor knew about the defect.

Listeria monocytogenes: A soil-associated bacterium that can contaminate both animal- and vegetable-based foods. Carrier animals can be symptom-free and contaminate meat and dairy products; vegetables can be contaminated by soil or manure used as fertilizer. It is found in both uncooked and processed vegetables, meats, and dairy products. Listeriosis presents symptoms such as stomach cramps, nausea, vomiting, diarrhea, and fever. Infections can also affect a person by means of septicemia, meningitis, encephalitis, or meningoencephalitis. The CDC attributed about 1,600 illnesses and 260 fatalities to L. monocytogenes in 2014.

Lot: The food produced during a period of time indicated by a specific code. This could mean a batch, or specific identified portion of a batch, having uniform character and quality within specified limits.

M

Market withdrawal: The removal or correction by a company of a distributed product that involves minor violations not subject to FDA legal action, or that involves non-violations such as normal stock rotation practices, routine equipment adjustments and repairs, etc.

Microbial contamination: Product adulteration by harmful bacteria or spoilage organisms through production errors or equipment malfunctions, human error, and other reasons. (Also see contamination). 
Misbranding: The false or misleading labeling of a food or drug product. A misbranded product may be subject to recall if the label or packaging mistakes nutrient composition or excludes ingredients. Action is especially likely if the product in question involves one of the "Big 8" allergens: eggs, fish, shellfish, milk, peanuts, tree nuts (walnuts, cashews, etc.), soy, and wheat.

Mock Recall: Mock recalls are practice exercises conducted by manufacturers and processors, along with various partners in the supply chain to assess their recall procedures and responsiveness during normal (non-recall) operations.

N

National Animal Health Laboratory Network (NAHLN): The NAHLN is part of a nationwide program that enhances the Nation's early detection of, response to, and recovery from animal health emergencies. It consists of partnership of over 60 federal, state and universityassociated animal health laboratories distributed throughout the U.S.

\section{National Antimicrobial Resistance Monitoring System for Enteric Bacteria (NARMS): A} monitoring collaboration made up of three federal agencies: Food and Drug Administration (FDA), Centers for Disease Control and Prevention (CDC), and the Food Safety and Inspection Service (FSIS) in the US Department of Agriculture (USDA). NARMS tests the antibiotic resistance of gastrointestinal bacteria to determine resistance patterns that may be useful in outbreak investigations.

National Center for Emerging and Zoonotic Infectious Diseases (NCEZID): Part of the Centers for Disease Control and Prevention (CDC). Its goal is to prevent illness, disability, and death caused by infectious diseases in the US and around the world. It conducts surveillance, epidemic investigations, epidemiologic and laboratory research, training, and public education programs to develop, evaluate, and promote prevention and control strategies for infectious diseases. Website is http://www.cdc.gov/ncezid/. 
National Labeling and Education Act (NLEA): The NLEA of 1990 provides FDA with specific authority to require nutrition labeling of most foods regulated by the Agency; and to require that all nutrient content claims (e.g., 'high fiber', 'low fat', etc.) and health claims be consistent with agency regulations.

\section{National Molecular Subtyping Network for Foodborne Disease Surveillance_(PulseNet):}

A data-gathering network of public health laboratories in the United States and Canada overseen by the CDC. Provides supplemental data on food-related pathogens and related diseases, including a DNA test called pulsed-field gel electrophoresis (PFGE) that can be used to identify specific strains and origins of bacteria. The labs make the results available on PulseNet for quick comparison. (Online at https://www.cdc.gov/pulsenet/). See also PulseNet International, below.

National Plant Diagnostic Network (NPDN): The NPDN was established in 2002 in response to the need to enhance agricultural security through protecting health and productivity of plants in agricultural and natural ecosystems in the U.S. The network is supported by the USDA-NIFA and through the collective efforts of many Land Grant Universities, federal agencies, state departments of agriculture, and other stakeholders.

Negligence: Failure to exercise the appropriate and or ethical ruled care expected to be exercised amongst specified circumstances.

Noncompliance Report (NR): A document issued by a Compliance Officer for FSIS or the FDA to a company owner or plant manager indicating it must take immediate action to remedy a problem uncovered in an inspection. (Also see Process Deficiency Report).

Office of Criminal Investigation (OCI): Established to provide the Food and Drug Administration (FDA) with a specific Office to conduct and coordinate criminal investigations. 
Office of the Inspector General (OIG): Establishment in 1976, the OIG of the U.S. Department of Health \& Human Services (HHS) was established as an effort to fight waste, fraud, and abuse in more than 100 other HHS programs.

\section{$\mathbf{P}$}

Pathogen: A bacterium, virus, parasite, or other infectious agent capable of causing a disease or illness.

Period codes: Manufacturing data used by companies to identify the approximate date and time a product was made. Period codes can play a vital role in determining how big a recall must be. A company using one-or two-hour period codes, for example, may be able to significantly reduce the amount of recalled product compared to a company that uses half- or full-day codes, simply because individual production lots can be traced more accurately.

Poultry Products Inspection Act (PIA): The federal law that authorizes the FSIS to regulate the slaughter, processing, and distribution of poultry products with uniform inspection standards. It includes language that the condemnation of products be "supported by scientific fact, information, or criteria." For the full text of the act, see https://www.fda.gov/RegulatoryInformation/LawsEnforcedbyFDA/ucm148721.htm

Press kit: A folder of written materials about a company or event prepared for the news media. It may contain company history, product news, and/or information about topics that may be of interest to reporters for story ideas.

Preventive Control: Measures that are required to ensure that hazards requiring a preventive control will be minimized or prevented. They include process, food allergen, and sanitation controls, as well as supply-chain controls and a recall plan.

Preventive Controls Qualified Individual PCQI: “Refers to a qualified individual who has successfully completed training in the development and application of risk-based preventive controls at least equivalent to that received under a standardized curriculum recognized as 
adequate by FDA or is otherwise qualified through job experience to develop and apply a food safety system.

Process Deficiency Report (PDR): A document issued by a compliance officer for FSIS or the FDA to a company owner or plant manager indicating it must take immediate action to remedy a problem uncovered in an inspection. (Also see Noncompliance Report).

Product: An article subject to the jurisdiction of the Food and Drug Administration, including any food, drug, or device intended for human or animal use, any cosmetic or biologic intended for human use, and any item subject to FDA quarantine (21 CFR, 1240). The term "product" does not include an electronic product that emits radiation (21 CFR, 1003, 1004).

\section{Product withdrawal See Market withdrawal.}

Public warning: In the cases of recalls involving an immediate threat to public health, the FDA will, in consultation with the recalling company, alert the public that a product being recalled presents a serious health hazard. It is reserved for urgent situations where other means for preventing use of the recalled product appear inadequate.

PulseNet: See National Molecular Subtyping Network for Foodborne Disease Surveillance above.

PulseNet International: A network of more than 120 pulsed-field gel electrophoresis laboratories in 82 countries similar to the US one described above. (Online at http://www.pulsenetinternational.org/)

Punitive damages: This is an amount awarded by a court in excess of normal compensation to "punish" a defendant for serious wrongdoing. There are numerous court cases in which companies defeated punitive damage claims because they acted quickly, comprehensively and cooperatively to recall defective products. 
Recall: A company's removal from distribution and sale of a marketed product against which the FDA could initiate legal action, e.g., seizure. The product may be unsafe, adulterated, contaminated, or mislabeled; or the FDA may consider it to be in violation of federal law. Recall does not include market withdrawals or stock recovery.

Recall classification: The FDA designation (Class I, II, or III), assigned to product recalls to indicate the relative health hazard of the recalled product.

Recall coordinator: The recall coordinator leads the company's recall team and supervises the making of a recall plan. He or she should have comprehensive knowledge of the company and its products and enough authority to make and execute key decisions quickly and communicate them to the company officers.

Recall, FDA-requested: Under 21 CFR, 7.45, the commissioner of the Food and Drug Administration (FDA) or the commissioner's designee may ask a company to initiate a recall when it is determined that the product in question may threaten the public health or safety if not recalled, or be a "gross consumer deception," if the company has not recalled the product voluntarily.

Recalling firm: The company initiating a recall, or, in the case of a FDA-requested recall, the company with primary responsibility for the manufacture and marketing of the recalled product.

Recall number: The number assigned by the FDA to a particular recall action. Separate recall numbers may be assigned if the product in question was reprocessed or used in the manufacture of another product.

Recall plan: A written set of procedures, practices, and actions developed and put in place for a particular company or type of product in case a product recall becomes necessary. (See also recall strategy.) 
Recall status reports: Companies recalling products are asked by the FDA or FSS to submit periodic recall status reports to the relevant FDA district office. Status report frequency is flexible and will be specified by the FDA depending upon recall urgency. (21 CFR, 7.53).

Recall strategy: A company's planned, specific course of action to be taken in conducting a recall, which addresses the depth of recall, need for customer and public warning, and extent of effectiveness checks for the recall.

Recall team: A group of key personnel from different areas of a company, along with external experts in other fields. This team should meet regularly to consider possible health and safety hazards, recommend corrections, decide on the company's recall strategy, draft a written recall plan, and conduct mock recall exercises to prepare for the possibility of a product emergency. Recall termination: The FDA terminates a recall when it determines that all reasonable efforts have been made to remove or correct the product in accordance with the recall strategy. Notice of recall termination will be issued in writing by the relevant district office. (21 CFR 7.55).

Reimbursement, customer: A method by which a customer's or client's money is refunded. To maintain good customer relations and reduce the number of possible claims against the company, guidelines for refunding customers' money in the event of a recall should be considered as part of the company recall strategy.

Reportable Food Registry (RFR): An electronic portal monitored by the FDA where registered food facilities that pack, process, manufacture, or hold food products are required to report cases of "reasonable probability" that a food will cause serious adverse health consequences to people or animals. Local, state, and federal government agencies can also voluntarily use the RFR portal to disseminate information about reportable foods. RFR website is http://www.fda.gov/Food/ComplianceEnforcement/RFR/default.htm.

Responsible individual (or party): The FDA's term for any person within a company who is in a position of power or authority to prevent, detect, or correct violations of the Federal Food, Drug, and Cosmetic Act. 
Risk management: The part of the recall team that knows the details of the company's recallrelated insurance coverage.

S

Sabotage: The deliberate destruction of property or the tainting or hindering of a manufacturing process by someone unhappy with a company or employer. Food supply sabotage must be incorporated as a possible bioterrorism and/or security threat and included in safety precautions and recall planning. (See Bioterrorism, Tampering).

Salmonella: A genus of bacterial pathogens that live in the intestines of birds, reptiles, and mammals, and spread to humans through animal-based foods. Can enter the bloodstream and cause food poisoning and potentially fatal infections like typhoid and septicemia in children, the elderly, and people in poor health. In 2014, the CDC estimated Salmonella species were responsible for 1.2 million foodborne illness cases and 450 deaths.

Sanitation Standard Operating Procedures (SSOPs): Required safety and sanitation procedures for federally inspected meat and poultry plants. (Also see HACCP).

Seizure: A formal move by the FDA (with the legal backing of a court order) to take possession of products in order to remove them from the commerce stream if its request for a voluntary recall is ignored or not adequately addressed by the target company.

Shellfish: A common allergen, this category of seafood includes clams, mussels, oysters, and scallops.

Safe Quality Food (SQF): SQF is a food-safety certification standard. SQF-certified companies have successfully completed a certification audit by a third-party auditor showing that their food-safety system meets the requirements of the SQF code. There are two levels, SQF 2 (food safety) and SQF 3 (food safety and quality).

Shigella: A genus of bacteria that can cause fever, cramps, diarrhea, and, often, bloody bowel movements. It remains in the stool of infected people for up to two weeks after illness, which 
makes hand-washing extremely important to avoid spreading infection. Shigella can be acquired from contaminated food or by drinking or swimming in contaminated water. Shigellosis, the illness caused by ingesting the Shigella bacterium, typically lasts from 5 to 7 days, but the person may still be infectious for another two weeks after symptoms subside. In 2014, the CDC estimated Shigella sickened 500,000 people and caused 40 deaths.

Statutes of limitation: Like liability and duty-to-recall laws, statutes of limitation vary widely from state to state. Companies can reduce liability exposure by thoroughly understanding statutes of limitation for their products in the states where they are sold.

Strict liability: Is a standard for liability which may exist in either a criminal or civil context. A rule specifying strict liability makes a person legally responsible for the damage and loss caused by his/her acts and omissions regardless of culpability.

Stock keeping units (SKUs): A type of item for sale such as a product or service. Attributes associated with the item distinguish it from other item types. These attributes could include manufacturer, description, material, size, color, packaging, and warranty terms.

Stock recovery: A company's collecting of a product from its distributors or warehouses that has not left the company's direct control and of which no portion has been released for sale or use.

Sulfites: Sulfur-based preservatives that are used in many types of cooked and processed foods and occur naturally in beer and wine. The FDA estimates about 1 out of 100 people is sulfitesensitive, as well as about 5 percent of asthma sufferers. FDA requires that the presence of sulfites be disclosed on food labels.

T

Tampering: Interfering with the production, content, or labeling of a food, drug, or device with the intent of changing it for the worse.

Threat: The intention and capability of an adversary to undertake actions that would be detrimental to critical infrastructures; a person or thing likely to cause damage or danger. 
Tree nuts: This common food-allergen category includes almonds, Brazil nuts, cashews, filberts or hazelnuts, macadamia nuts, pecans, pine nuts, pistachios, and walnuts.

U

United States Department of Agriculture (USDA): A large federal agency with wide-ranging responsibilities that was first created as "the People's Department" by President Abraham Lincoln in 1862 to help farmers. Today, the USDA administers Food Stamp, and School Breakfast and Lunch Programs; serves as a water and soil conservation agency; funds rural housing projects; and much more. The USDA is also responsible for the safety of meat, poultry, and egg products through its Food Safety and Inspection Service (FSIS). (www.usda.gov)

United States Department of Health and Human Services (DHHS): The US government's principal agency for protecting the health of all Americans and providing essential human services, especially for those least able to help themselves. There are more than $300 \mathrm{DHHS}$ programs for food and drug safety, disease prevention, and response to disease outbreaks. The DHHS includes the Food and Drug Administration (FDA) and the Centers for Disease Control and Prevention $(C D C)$, two federal agencies involved with product recalls. For detailed information on DHHS, go to www.hhs.gov

V

Vulnerability: A weakness in the design, implementation, or operation of an asset or system that can be exploited by an adversary, or disrupted by a natural hazard or technological failure

W

Willful blindness: A legal term for a phenomenon wherein companies or employees intentionally put adulterated food into the commerce stream. Proof of willful blindness can turn possible misdemeanors into felonies, with their attendant increases in criminal penalties and fines. 


\section{Appendix 1-1: Links to Important Food Recall and Food Safety Resources}

From the FDA's Food Safety home page you can access a wealth of information, including the agency's food guidance documents (by year and topic). The site hosts an extensive section on food defense and how to guard against intentional adulteration of foods; safety information about additives and packaging; and discussion of current good manufacturing practices (CGMPs).

http://www.fda.gov/Food/default.htm

On FDA's compliance and enforcement page, you can access the Reportable Food Registry (RFR) and numerous documents, including the Regulatory Procedures Manual (RPM) and Investigations Operations Manual (IOM), and you can see the FD\&C Act: http://www.fda.gov/Food/ComplianceEnforcement/default.htm

On FDA's industry guidance page, you can find templates for letters to announce a product recall, a response form for distributors and wholesalers, and sample letters and forms for conducting effectiveness checks.

http://www.fda.gov/Safety/Recalls/IndustryGuidance/default.htm

The best way to see what the FDA says in its own recall communications is to look at the website where all of them are posted:

http://www.fda.gov/Safety/Recalls/

See the full text of the Food Safety and Modernization Act (FSMA) on this website: http://www.fda.gov/Food/GuidanceRegulation/FSMA/ucm359436.htm

A list of FDA Office of Regulatory Affairs personnel and contact information is online at: http://www.fda.gov/downloads/ICECI/Inspections/IOM/UCM123522.pdf 
The USDA's Food Safety and Inspection Service (FSIS) offices and contact information can be found online at:

http://www.fsis.usda.gov/wps/portal/informational/districtoffices

The USDA FSIS website is very consumer-oriented but contains helpful links for industry in their sections on Regulations and Policies, and Recalls.

http://www.fsis.usda.gov/wps/portal/fsis/home

USDA has a 52-page report titled "How to Develop a Meat and Poultry Recall Plan," at http://www.fsis.usda.gov/shared/PDF/RecallPlanBooklet_0513.pdf, and an extensive Directive on recall of meat and poultry products online at http://www.fsis.usda.gov/wps/wcm/connect/77a99dc3-9784-4a1f-b694ecf4eea455a6/8080.1.pdf?MOD=AJPERES

The FSIS page of forms (http://www.fsis.usda.gov/wps/portal/fsis/forms/fsis-forms) includes FSIS-5420-5, a General Food Defense Plan, a template that can be downloaded and filled out by meat-processing facilities.

On the FDA guidance page, you can access the Public Warning and Notification of Recalls Under 21 CFR Part 7, Subpart C Guidance for Industry and FDA Staff: https://www.fda.gov/downloads/Safety/Recalls/IndustryGuidance/UCM592851.pdf 


\section{Appendix 1-2: Call Sheet for Persons Claiming an Illness or Injury}

This is a rather lengthy questionnaire, but it covers everything. If the person on the phone indicates frustration that "It's taking too long," reassure them: "We want to confirm all the facts so that we can make the best decision about what to do next. Thank you so much for your patience."

Date and time of incoming call

Who received the call?

Name of person calling

Phone number(s) where you can be contacted

Email where you can be contacted

Which product did you call to discuss?

Packaging specifics (size, product code, sell-by date, etc.)

Where was this product purchased?

When was this product purchased?

How was the product stored before use?

How was it used or prepared?

Describe the problem as specifically as you can (odor, color, taste, object in the food, allergic reaction, etc.)

Name and age of person who is illor injured

Contact information (if different than above)

What are the person's symptoms? 
In what order did the symptoms appear?

Do you know if this person has any other injuries orallergies?

Can we send you a Food Diary to fill out, to help with our investigation?

Did anyone else consume the product at thesame time?

Are they having similar symptoms?

Has the person seen a doctor for this problem? If so, when?

Was there a diagnosis?

Doctor's name and contact information

Have you reported this incident to anyone else? If so, whom?

Do you still have any of the product?

Do you have the original packaging?

(If so, tell them to KEEP THESE; DO NOT throw them away!)

Can we send someone to pick up the productfor testing?

(If so, get a street address)

Is there something specific you are asking (the company) to do, or considerdoing?

\section{Thank the caller for being concerned enough to contact the company.}

- Thank them sincerely for their time.

- Tell them, "We will make sure your complaint is investigated, and if we have any other questions, someone from the company will contact you.

- Do not promise to do anything other than look into the complaint and passthe information along for investigation. 
Signature of person who took the call

Printed name of person who took the call

Date and time this report was completed

\section{Follow-Up Action Taken}

Who in the company received the initial report?

\begin{tabular}{|l|l|}
\hline Date of Follow-up Action & Description of Follow-up Action \\
\hline & \\
\hline & \\
\hline & \\
\hline & \\
\hline & \\
\hline
\end{tabular}

Brief Summary of Complaint Resolution 
Appendix 1-3: Food Diary Form

DATE:

NAME OF PERSON AFFECTED:

NAME OF PERSON FILLING OUT THIS FORM:

\section{CONTACT INFORMATION:}

PHONE: (circle one: Home Work Cell)

EMAIL ADDRESS:

Thank you for reporting your recent experience to

(Company Name)

To help us determine the cause of your complaint, it is important that we know, to the best of your recollection, what you ate on the day you experienced the problem, as well as what you ate for the previous two days. Please fill out this form as completely as possible and return it to us. We appreciate your time. 
DATE

(day 1, two days before symptoms occurred)

\begin{tabular}{|l|l|}
\hline Meal & Foods and beverages ingested \\
\hline Breakfast & \\
\hline Lunch & \\
\hline Dinner & \\
\hline Other (between-meal \\
snacks \& beverages)
\end{tabular}

DATE

(day 2, one day before symptoms occurred)

\begin{tabular}{|l|l|}
\hline Meal & Foods and beverages ingested \\
\hline Breakfast & \\
\hline Lunch & \\
\hline Dinner & \\
\hline Other (between-meal & \\
\hline snacks \& beverages) & \\
\hline
\end{tabular}


DATE

(day 3, the day that symptoms occurred)

\begin{tabular}{|l|l|}
\hline Meal & Foods and beverages ingested \\
\hline Breakfast & \\
\hline Lunch & \\
\hline Dinner & \\
\hline Other (between-meal & \\
snacks \& beverages) & \\
\hline
\end{tabular}




\section{Appendix 1-4: Call Sheet in Case of a Telephone Threat}

Threatening callers often begin by stating something like, "Listen carefully: I'm only going to say this once." The caller usually insists on setting "ground rules" for the conversation. You might be frightened, but it is critical that you remain calm and give the person your full attention. Your goal is to obtain as much information as possible-from the caller and about the caller-as you listen. Take notes.

Complete this form immediately after taking the threatening call, and report the incident immediately, as outlined in your company's emergency policy.

Date and time of incoming call

Who received the call?

Did the caller identify themselves?

If your caller ID system showed a number, write it here

What did the caller say (exact words or phrases youremember)?

What threat was made?

What demand was made?

Did the person say they would call again? If so, when?

Could you tell how old the caller was?

Adult Teen

Child Approx. Age 
Did you notice an accent?

Did you notice any other speech characteristics (word use or pronunciation, lisp, stutter, etc.)?

List anything else you noticed about the caller's voice.

Describe any specific background noises you heard on thecall.

How would you describe how the caller was acting?

Calm

Nervous

Rational

Irrational

Any other characteristics of voice or demeanor?
Excited

Laughing
Shouting

Angry

Enraged

What did you say to the caller?

How did the call end? Who ended it? 
Signature of person who took the call

Date and time this report was completed

Printed name of person who took the call

\section{Follow-Up Action Taken}

Who in the company received the written threatreport?

Was law enforcement contacted? Was a police report filed?

Which law enforcement agency, and when?

Contact information for law enforcement

\begin{tabular}{|l|l|}
\hline Date of Follow-up Action & Description of Follow-up Action \\
\hline & \\
\hline & \\
\hline & \\
\hline & \\
\hline & \\
\hline & \\
\hline
\end{tabular}


Other Notes 


\section{Appendix 1-5: Product Recall Checklist}

This checklist is a basic, general log of actions that includes all major actions and requirements. It may easily be adapted in greater detail to fit a company's specific Recall Plan. Remember, many of these steps will be taken simultaneously.

\section{Recall Team and Preliminary Steps}

\begin{tabular}{|c|c|c|c|}
\hline Action & Initiated & Completed & Not Done \\
\hline \multicolumn{4}{|l|}{ Select and organize recall team } \\
\hline \multicolumn{4}{|l|}{ Select team leader (or recall coordinator) and PCQI } \\
\hline \multicolumn{4}{|l|}{ Select and interview outside experts, consultants } \\
\hline \multicolumn{4}{|l|}{ Hire outside experts and consultants } \\
\hline \multicolumn{4}{|l|}{ Distribute contact list to all team members } \\
\hline \multicolumn{4}{|l|}{ Select and train team spokesperson } \\
\hline \multicolumn{4}{|l|}{$\begin{array}{l}\text { Communicate with dept. managers about plan and recall } \\
\text { team's upcoming tour }\end{array}$} \\
\hline \multicolumn{4}{|l|}{$\begin{array}{l}\text { Recall team tours company facilities and customer sites } \\
\text { and makes recommendations }\end{array}$} \\
\hline \multicolumn{4}{|l|}{ Prioritize risks and tour findings (high, med, or low) } \\
\hline \multicolumn{4}{|l|}{ Solicit suggestions for improvements } \\
\hline \multicolumn{4}{|l|}{$\begin{array}{l}\text { Assess employee and dept. management morale, } \\
\text { commitment to improvements }\end{array}$} \\
\hline \multicolumn{4}{|l|}{$\begin{array}{l}\text { Review FDA or FSIS guidelines, FSMA recommendations, } \\
\text { pertinent local laws }\end{array}$} \\
\hline \multicolumn{4}{|l|}{ Review product tracking systems: } \\
\hline \multicolumn{4}{|l|}{ For receiving } \\
\hline \multicolumn{4}{|l|}{ For manufacturing } \\
\hline \multicolumn{4}{|l|}{ For distribution } \\
\hline \multicolumn{4}{|l|}{ Approve document templates: letters, news releases, etc. } \\
\hline \multicolumn{4}{|l|}{$\begin{array}{l}\text { Prepare company internal contact list (includes recall } \\
\text { contact person at each facility) }\end{array}$} \\
\hline \multicolumn{4}{|l|}{ Prepare customer/consignee contact list } \\
\hline \multicolumn{4}{|l|}{ Create scenario \& "rules" for Mock Recall } \\
\hline \multicolumn{4}{|l|}{ Perform Mock Recall exercise } \\
\hline \multicolumn{4}{|l|}{$\begin{array}{l}\text { Modify Recall Plan as necessary based on Mock Recall } \\
\text { results }\end{array}$} \\
\hline Get legal review of final plan & & & \\
\hline
\end{tabular}




\section{The Recall Decision}

\begin{tabular}{|l|l|l|l|}
\hline Action & Initiated & Completed & Not Done \\
\hline Recall team notified of problem & & & \\
\hline Recall team briefed by legal counsel & & & \\
\hline Dept. managers briefed on problem and asked for & & & \\
input & & & \\
\hline FSMA, other pertinent FDA or FSIS laws, rules reviewed & & & \\
\hline Dept. managers submit records to Recall Team & & & \\
\hline Risk evaluated & & & \\
\hline Decision made to initiate a: & & & \\
\hline Stock recovery & & & \\
\hline Market withdrawal & & & \\
\hline Product recall & & & \\
\hline If decision is internal, notify FDA & & & \\
\hline Team spokesperson, communications staff prepare info & & & \\
\hline
\end{tabular}


Immediate Actions

\begin{tabular}{|l|l|l|l|}
\hline Action & Initiated & Completed & Not Done \\
\hline Halt product production & & & \\
\hline $\begin{array}{l}\text { Begin internal investigation to determine cause or } \\
\text { source of problem }\end{array}$ & & & \\
\hline Secure product in warehouse & & & \\
\hline $\begin{array}{l}\text { Brief receptionists, admins on what to tell incoming } \\
\text { callers and what info to obtain from them }\end{array}$ & & & \\
\hline $\begin{array}{l}\text { Decide whether potential call volume will necessitate } \\
\text { hiring a call center }\end{array}$ & & & \\
\hline Compile information for Reportable Food Registry & & & \\
\hline Update website with recall info & & & \\
\hline
\end{tabular}

\section{Gather Information}

\begin{tabular}{|l|l|l|l|}
\hline Action & Initiated & Completed & Not Done \\
\hline Pinpoint identity of product(s) & & & \\
\hline $\begin{array}{l}\text { Establish use of reworked or blended ingredients and } \\
\text { their suppliers }\end{array}$ & & & \\
\hline Determine the product package size(s) & & & \\
\hline Record product code number(s) & & & \\
\hline Record production date(s) & & & \\
\hline Determine quantity per code date & & & \\
\hline Establish location of each shipment & & & \\
\hline Verify quantity in controlled warehouses & & & \\
\hline Verify quantity shipped to customers & & & \\
\hline Determine quantity of product unaccounted for & & & \\
\hline
\end{tabular}


Recall Classification and Depth

\begin{tabular}{|l|l|l|l|}
\hline Action & Initiated & Completed & Not Done \\
\hline Agency (FDA or USDA-FSIS) assigns recall classification & & & \\
\hline Agency (FDA or USDA-FSIS) assigns recall number(s) & & & \\
\hline $\begin{array}{l}\text { Depth of recall (might be determined by agency or by } \\
\text { recall team) }\end{array}$ & & & \\
\hline $\begin{array}{l}\text { Revise document templates to reflect current situation, } \\
\text { recall classification, and depth }\end{array}$ & & & \\
\hline $\begin{array}{l}\text { Update dept. managers about recall classification and } \\
\text { depth }\end{array}$ & & & \\
\hline
\end{tabular}

\section{Notification to Outside Groups}

\begin{tabular}{|l|l|l|l|}
\hline Action & Initiated & Completed & Not Done \\
\hline Notify wholesale distributors by phone/fax & & & \\
\hline Notify wholesale distributors by email or mail & & & \\
\hline Notify retailers by phone/fax & & & \\
\hline Notify retailers by email or mail & & & \\
\hline FDA or FSIS request for news release & & & \\
\hline Send news releases as needed & & & \\
\hline Update sales reps about recall, what to tell customers & & & \\
\hline Finalize info for sales reps to deliver to retail customers & & & \\
\hline Update website as needed & & & \\
\hline
\end{tabular}


Product Disposition

\begin{tabular}{|l|l|l|l|}
\hline Action & Initiated & Completed & Not Done \\
\hline $\begin{array}{l}\text { Make decisions for how to collect and/or dispose of } \\
\text { product }\end{array}$ & & & \\
\hline Decide on policies for refunds or exchanges & & & \\
\hline Inform wholesalers about product disposition & & & \\
\hline Inform retailers about product disposition & & & \\
\hline Sales reps help customers to comply with recall & & & \\
\hline Customer service briefed on refund policy & & & \\
\hline Warehouse prepared to receive product & & & \\
\hline Warehouse isolates returned product & & & \\
\hline
\end{tabular}

Effectiveness Checks

\begin{tabular}{|l|l|l|l|}
\hline Action & Initiated & Completed & Not Done \\
\hline FDA effectiveness check Level established & & & \\
\hline Effectiveness checks begin & & & \\
\hline Finish date established & & & \\
\hline Review/evaluate effectiveness checks & & & \\
\hline Prepare effectiveness checks summary & & & \\
\hline
\end{tabular}

\section{Recall Termination}

\begin{tabular}{|l|l|l|l|}
\hline Action & Initiated & Completed & Not Done \\
\hline FDA or FSIS notified of recall completion & & & \\
\hline Recall officially concludes & & & \\
\hline $\begin{array}{l}\text { Team receives written confirmation from FDA or FSIS of } \\
\text { recall completion }\end{array}$ & & & \\
\hline $\begin{array}{l}\text { Announcement (and thanks) to customers about } \\
\text { successful end of recall }\end{array}$ & & & \\
\hline Update website & & & \\
\hline
\end{tabular}


Final Steps

\begin{tabular}{|l|l|l|l|}
\hline Action & Initiated & Completed & Not Done \\
\hline $\begin{array}{l}\text { Recall team assembles all documents for thorough } \\
\text { review of recall }\end{array}$ & & & \\
\hline $\begin{array}{l}\text { Team reviews all procedures and makes } \\
\text { recommendations to senior management }\end{array}$ & & & \\
\hline Team decides on exact cause of problem & & & \\
\hline Recall coordinator writes summary report & & & \\
\hline Necessary corrections made & & & \\
\hline $\begin{array}{l}\text { Final report reviewed; presented to senior } \\
\text { management }\end{array}$ & & & \\
\hline
\end{tabular}




\section{LIST OF SOURCES}

The University of Florida Department of Food Science and Human Nutrition is extremely grateful to the following organizations and individuals for sharing their suggestions and expertise, as well as information from their texts, articles and other documents, and websites:

Association of Food and Drug Officials (AFDO), York, PA (www.afdo.org)

The Bad Bug Book (Foodborne Pathogenic Microorganisms and Natural Toxins Handbook), U.S. Food and Drug Administration

(https://www.fda.gov/food/foodborneillnesscontaminants/causesofillnessbadbugbook/)

Centers for Disease Control and Prevention, Atlanta, GA. (www.cdc.gov)

Code of Federal Regulations, Rules and Regulations 2013-2015, Federal Register.

(https://www.federalregister.gov)

Damage Control (D. Scholz), Marketing Magazine, Rogers Digital Media, Toronto, Ontario, May 25, 2009 (http://marketingmag.ca/brands/damage-control-8750/)

The Department of Homeland Security's Role in Food Defense and Critical Infrastructure Protection, Dept. of Homeland Security. (https://www.oig.dhs.gov/assets/Mgmt/OIG 0733 Feb07.pdf)

Explaining Differences Between HACCP and HARPC (L. Maloy), Food Online, Erie, PA, Feb. 27, 2015 (https://www.foodonline.com/doc/explaining-differences-between-haccp-and-harpc$\underline{0001)}$

Federal Food Safety Laws, National Conference of State Legislatures. (http://www.ncsl.org/research/agriculture-and-rural-development/federal-food-safetylaws.aspx)

FindLaw.com, Eagan, MN. (www.findlaw.com)

Florida Dept. of Agriculture and Consumer Services, Division of Food Safety, Tallahassee, FL. (http://www.freshfromflorida.com/Divisions-Offices/Food-Safety)

Food Allergy \& Anaphylaxis Connection Team (FAACT), West Chester, $\mathrm{OH}$ (www.foodallergyawareness.org)

Food Allergy Research \& Education (FARE), McLean, VA. (www.foodallergy.org)

Food Defense Plan: Security Measures for Food Defense, U.S. Dept. of Agriculture Food Safety and Inspection Service. (https://www.fsis.usda.gov/wps/wcm/connect/376b1a10-b029-46b89848-52e6b743d0bb/Form-5420-6-Food-Defense-Plan-Siluriformes-Fish.pdf?MOD=AJPERES) 
Food Defense Whitepaper Series, Parts 1-3, Tyco Integrated Security, Princeton, N.J. (https://www.tycois.com/insights-and-opinions/all-business-sizes/white-papers)

Food Industry Recall Protocol, Food Standards Australia New Zealand (http://www.foodstandards.gov.au/industry/foodrecalls/firp/pages/default.aspx)

Food Quality and Safety Magazine, Hoboken, NJ. (www.foodqualityandsafety.com)

Food Safety Enforcement and Inspection Actions and Terminology, USDA Food and Nutrition Service. (www.fns.usda.gov/sites/default/files/fdd/FSIS-Terminology-White-Paper.pdf)

Food Safety News (multiple articles, 2015-2016), Dan Flynn, editor (www.foodsafetynews.com) Herrick Feinstein, LLP, New York, N. Y. (www.herrick.com)

Integrating the Nation's Food Safety System: What You Need to Know (G. Ades, B. Cassens, J. Corby, J. Farrar, J. Holthaus Badour, P. Kennelly, S. Mandernach and S. Stromberg), Food Safety magazine, Glendale, Calif., April-May 2016 (https://www.foodsafetymagazine.com/magazinearchive1/aprilmay-2016/integrating-the-natione28099s-food-safety-system-what-you-need-toknowpast-present-and-future/)

International Risk Management Institute (IRMI), Dallas, Texas (www.irmi.com)

Investigations Operations Manual 2016, U.S. Food and Drug Administration. (https://www.fda.gov/iceci/inspections/iom/default.htm)

Margulies, D., president, Margulies Communications Group, 2016, Personal Communication.

Marler, B., founding partner, Marler Clark, 2005 and 2016, Personal Communication.

Office of the Inspector General, U.S. Dept. of Health and Human Services. (https://oig.hhs.gov)

Partnership for Food Safety Education, Arlington, VA. (www.fightbac.org)

Questions \& Answers on the Food Safety Modernization Act (March 2016), U.S. Food and Drug Administration. (https://www.fda.gov/food/guidanceregulation/fsma/ucm247559.htm)

Small Scale Food Processor Association (SSFPA), Nanaimo, British Columbia (www.ssfpa.net)

Reportable Food Registry at a Glance, U.S. Food and Drug Administration. (https://www.fda.gov/Food/ComplianceEnforcement/RFR/default.htm)

Resch, M., executive vice president of administration and general counsel, Amy's Kitchen, Inc., 2016, Personal Communication. 
Responding to a Food Recall: Procedures for Recalls of USDA Foods, USDA and National Food Service Management Institute, University of Mississippi. (https://fns-

prod.azureedge.net/sites/default/files/Responding Food Recall FNS Final May 30 2014.pdf)

Safe Quality Food Institute (SQI), Washington, DC. (www.sqfi.com)

U.S. Department of Agriculture (www.usda.gov)

U.S. Food and Drug Administration (www.fda.gov)

U.S. Food and Drug Administration (www.fda.gov). 2018. Public Warning and Notification of Recalls Under 21 CFR Part 7, Subpart C Guidance for Industry and FDA Staff.

(https://www.fda.gov/downloads/Safety/Recalls/IndustryGuidance/UCM592851.pdf)

Western Association of Food and Drug Officials, Anchorage, AK (www.wafdo.org)

Western Growers Association, Irvine, CA. (www.wga.com)

Writing Your New Playbook. M. Neumann), April 8, 2016. Quality Assurance \& Food Safety (http://www.qualityassurancemag.com/article/writing-your-new-playbook/) 